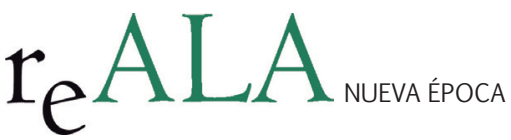

REALA, n 3, enero-junio 2015 ISSN: 1989-8975

DOI: http://dx.doi.org/10.24965/reala.voi3.10238

\title{
La iniciativa económica local tras la ley 27/2013, de 27 de diciembre, de racionalización y sostenibilidad de la administración local
}

\author{
Fernando García Rubio' \\ Profesor titular de Derecho Administrativo, Universidad Rey Juan Carlos
} fernando.rubio@urjc.es

\section{Resumen}

La reforma local de 2013 ha supuesto un cambio en el ámbito de la actividad y competencias locales que con respecto a la iniciativa económica de las entidades locales supone una absoluta supeditación al principio de estabilidad presupuestaria del art 135 de la Carta Magna de estas. Así el presente trabajo pretende analizar las nuevas determinaciones del art 86 LRBRL, tras la modificación de este por la ley 27/2013, de 27 de diciembre y las condiciones y formas de ejercicio de la actividad económica de las corporaciones locales partiendo del estudio desde la jurisprudencia , la doctrina, el derecho comunitario y la legislación estatal y autonómica de dicho ejercicio sus formas y modalidades, el procedimiento y los requisitos para ello, determinando el nuevo modelo de actividad económica local.

\section{Palabras clave}

Reforma local, iniciativa económica, sostenibilidad financiera, estabilidad presupuestaria, empresas, competencia, reserva de actividades, servicio público, municipalización, procedimiento, CC. AA. y tutela.

\section{Local economic initiative after the Law $27 / 2013$, of $27^{\text {th }}$ December, rationalization and sustainability of the local administration}

\section{Abstract}

The local reform of 2013 has been a change in the scope of activity and local powers with respect to economic initiative of local authorities is an absolute subordination to the principle of budgetary stability art 135 of the Magna Carta of these. So this paper analyzes the art 86 LRBRL new determinations, following the amendment of this by law 27/2013, of 27 December and the conditions and forms of exercise of economic activity of local government from the study from the jurisprudence, literature, Community law and national and regional legislation for that year its forms and modalities, the procedure and requirements for it, determining the new model of local economic activity.

Keywords

Local reform, economic initiative, financial sustainability, fiscal stability, businesses, competition, booking activities, public service, municipalization, procedure, CCAA protection.

$1 \quad$ El origen del presente trabajo es la intervención del autor en las jornadas técnicas sobre la reforma local celebradas en Almería los días 3 y 4 de abril de 2014, por la Universidad de Almería, el Instituto de derecho local de esta y la Diputación provincial, enmarcándose dentro del proyecto de investigación bajo su dirección INAP 44/2014, sobre las consecuencias de la ley de racionalización y sostenibilidad de la administración local. 


\section{PLANTEAMIENTO DE LA CUESTIÓN: LA NECESARIA REFORMA LOCAL}

Una de las escasísimas bondades de la profunda crisis económica en la que estamos inmersos es la necesidad perentoria, por imperativo económico, de mantenimiento del sistema, de reformar en profundidad las administraciones públicas.

Bajo ese parámetro, se vienen aprobando multitud de Decretos-Leyes desde el inicio, o más bien, desde la constatación de la crisis, dada la imposibilidad de financiar las entidades y servicios públicos con los ingresos tradicionales que regían el sistema administrativo derivado de la Constitución Española de 1978.

En ese sentido es paradigmática la reforma de la Constitución de septiembre de 2011, (la segunda, tras al reforma del art. 13.2 de la Carga Magna, para adecuarse al derecho de sufragio pasivo en las elecciones locales previsto para los nacionales de la Unión Europea en el Tratado de Maastricht de 1992), que estableció una nueva redacción para el art. 135 de la Ley de leyes², consagrando el principio de equilibrio presupuestario; lo que ha dado lugar a la posterior Ley Orgánica 2/2012, de 27 de abril de Estabilidad Presupuestaria y Sostenibilidad Financiera.

En dicha línea de sostenibilidad financiera del sector público en su conjunto, se ha venido exponiendo desde muy diversos sectores la imperiosa necesidad de proceder a una profunda reforma del conjunto de las administraciones públicas, especialmente en lo referido a la articulación de las competencias y el ejercicio de estas previsto por el Titulo VIII de la Constitución Española.

Partiendo de esto, debemos destacar que las reformas iniciadas tienen en el ámbito local una arquitectura y basamento legal centrada en una legislación básica estatal que hasta el momento se recoge en dicho ámbito en la Ley 7/1985, de 2 de abril, Reguladora de las Bases de Régimen Local.

Esta ley; que ha sido modificada en numerosas ocasiones, siendo las más importantes las realizadas por las leyes 11/1999, de 21 de abril, de modificación de la Ley 7/1985, de 2 de abril, Reguladora de las Bases de Régimen Local y otras medidas para el desarrollo del Gobierno Local, en materia de tráfico, circulación de vehículos a motor y seguridad vial y en materia de aguas, y la Ley 57/2003, de 16 de diciembre, de medidas para la modernización del gobierno local, es de necesaria referencia y, en su caso, revisión si pretende alterarse el sistema institucional y competencial del régimen local español, previsto en los arts. 140 a 142 de la Carta Magna de 1978.

Ahora bien, sin perjuicio de esa determinación básica estatal que se realiza al amparo del título competencial recogido en el art.149.1.18 , lo cierto es que el hecho autonómico plasmado en el Título VIII de la propia Constitución, establece un ámbito competencial para las Comunidades Autónomas en relación con el régimen local que ha sido específicamente ampliado por las reformas de los Estatutos de Autonomía de Cataluña, Andalucía, Comunidad Valenciana y Aragón; aprobados por Ley Orgánica 6/2006, de 19 de julio, de reforma del Estatuto de Autonomía de Cataluña, Ley Orgánica 2/2007, de 19 de marzo, de reforma del Estatuto de Autonomía para Andalucía, Ley Orgánica 1/2006, de 10 de abril, de Reforma de la Ley Orgánica 5/1982, de 1 de julio, de Estatuto de Autonomía de la Comunidad Valenciana, Ley Orgánica 5/2007, de 20 de abril, de reforma del Estatuto de Autonomía de Aragón y en menor medida Castilla y León, aprobado por Ley Orgánica 14/2007, de 30 de noviembre, de reforma del Estatuto de Autonomía de Castilla y León y Extremadura, aprobado por ley orgánica.

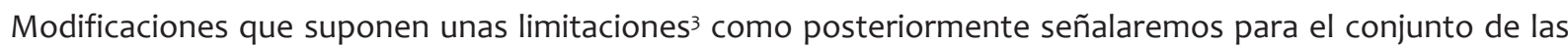
posibilidades reformadoras del legislador estatal, al menos en el sistema actual establecido por la interpretación del Tribunal Constitucional ${ }^{4}$ de dichos títulos competenciales y en buena medida para el régimen jurídico del ejercicio de la iniciativa económica local.

2 Al respecto de dicha reforma vid. Martín Bassols Coma,"La reforma del artículo 135 CE y la constitucionalización de la estabilidad presupuestaria: el proceso parlamentario de elaboración de la reforma constitucional”. Revista española de derecho administrativo $n^{\circ} 155$, págs. 21 a 41, julio-septiembre de 2012, Civitas, Thomson-Reuters.

3 Este fenómeno que ha sido denominado "interiorización” del derecho local y en general puede consultarse a Luis Cosculluela Montaner y Eloísa Carbonell Porras(directores)"Reforma Estatutaria y régimen local”, Civitas-Thomson Reuters , Ministerio de Ciencia e Innovación, 2011, debemos destacar que al amparo de los títulos competenciales recogidos en su estatuto de autonomía, diversas Comunidades Autónomas han aprobado legislaciones en relación a esta materia, que pretenden incidir en la línea de la "interiorización" del derecho local en las CCAA, y que han supuesto incluso antes de las reformas estatutarias del periodo 2006-2008, una impugnación de las capacidades legislativas del Estado sobre esa materia ante el Tribunal Constitucional, en los recursos 1523-2004 interpuesto por el Parlamento de Cataluña, $1598 / 2004$ interpuesto por el Gobierno Catalán y 1741/2004 promovido por el Gobierno de Aragón, que han sido resueltos por la STC 103/2013, de 25 de abril . Sobre esta materia véase con respecto a la interiorización Luis Ortega Álvarez "El régimen local en los nuevos estatutos de autonomía". Págs. 253 a 285 de "Tratado de Derecho Municipal” obra colectiva dirigida por Santiago Muñoz Machado, lustel 2011, y con respecto a los límites de la facultad legislativa en la organización de los servicios públicos locales del Estado, a Encarnación Montoya Martín “Las formas de gestión de los servicios públicos locales: los entes instrumentales.” Dentro del Congreso Europeo sobre descentralización territorial y administración local. Sevilla 9, 10 y 11 de mayo de 2007. Instituto Andaluz de Administración Pública 2009 pág.s 215 a 258.

4 Sobre el papel del alto interprete de la Carta Magna es imprescindible la obra de Germán Fernández Farreres,”la contribución del tribunal constitucional al estado autonómico", lustel , 2005. 
En cualquier caso, y pese al escaso importe en el conjunto del gasto público que las entidades locales tienen frente a las Comunidades Autónomas y a la Administración General del Estado, existe un amplio consenso en la necesidad de abordar con urgencia un conjunto de reformas del régimen local, que no sólo se vinculan con la contención del gasto y la racionalización de este, sino que pretenden tener más alcances.

Al amparo de dicho impulso reformista, se creó en el seno del Instituto Nacional de Administración Pública, una Comisión interadministrativa de estudio de la reforma local $^{6}$, que dio lugar a un documento objeto de debates que cristalizó en diversas versiones de anteproyecto de Ley para la racionalización y sostenibilidad de la administración local; el cual tras su estudio por el Consejo de Ministros en su sesión de fecha 15 de febrero de 2013, el dictamen de la comisión nacional de administración local de 21 de mayo de 2013 e innumerables reuniones, tanto en el seno de la Administración General del Estado, como con los colectivos afectados, fue remitido a dictamen del Consejo de Estado el día 26 de junio de 2013 y, posteriormente tras varios cambios de hondo calado, aprobado como proyecto de ley el 26 de julio de 2013 y finalmente tras diversas enmiendas en Congreso y Senado ,a la ley 27/2013,de 27 de diciembre, de racionalización y sostenibilidad de la Administración Local?.

Ahora bien, la reforma que se pretende abordar con la Ley de racionalización y sostenibilidad de la Administración local, pese a su ambicioso título, se centra, pese a la fundamentación de su exposición de motivos más ambiciosa, tan sólo en cuatro aspectos, tal y como se recoge en el párrafo tercero de la exposición de motivos, que señala de forma literal:

Que la reforma se plantea perseguir varios objetivos básicos, clarificar las competencias municipales para evitar duplicidades con las competencias de otras administraciones de forma que se haga efectivo el principio de "una administración una competencia" racionalizar la estructura organizativa de la administración local de acuerdo con los principios de eficiencia, estabilidad y sostenibilidad financiera, garantizar un control financiero y presupuestario más riguroso y favorecer la iniciativa económica privada evitando intervenciones administrativas desproporcionadas.

Por tanto, frente al importante calado que tiene, esta reforma deja al margen otros aspectos sustantivos que son ineludibles en relación con la reforma de la planta local en su conjunto, que dada la premura del tema de la financiación y la racionalización del sector público se dejan apartados para ulteriores ocasiones, desperdiciando, en opinión de la doctrina ${ }^{8}$, una oportunidad histórica.

Podemos resumir en base a esos cuatro objetivos, que nos encontramos con una ley "de crisis" y no aprobada como consecuencia de la crisis, con un enfoque absolutamente económico de ahorro del gasto público para reducir el déficit público (los famosos 7127 millones de euros de ahorro comprometidos por esta materia en el marco del MOU9), con vertientes en las estructuras y competencias. Todo ello bajo la óptica de la estabilidad presupuestaria derivada del art 135 de la Carta Magna y la L.O. 2/2012, de 27 de abril , con un posterior enfoque, (no se realizaba en los primeros borradores) de incentivación de la actividad económica particular, eliminando autorizaciones superfluas, pero no entrando en una reforma en profundidad del entramado institucional implantado en 1985.

\section{CARACTERÍSTICAS GENERALES DE LA REFORMA EN EL ÁMBITO DE LA INICIATIVA ECONÓMICA}

En concreto en lo que aquí interesa sobre la iniciativa económica, la Ley 27/2013, de 27 de diciembre, de racionalización y sostenibilidad de la administración local, realiza una profunda modificación de la LRBRL en materia

5 Al respecto vid el monográfico del anuario de derecho local 2012 "Racionalización y sostenibilidad de la Administración local: ¿Es esta la reforma?, dirigido por Tomas Font i LLovet y Alfredo Galán Galán. Fundación Democracia y gobierno local ,2012.

6 Dicho grupo sin reflejo en disposición específica alguna parte de una "Propuesta de modificación del articulado de la Ley 7/1985, reguladora de las bases del régimen local en relación de las competencias de las entidades locales (Grupo de colaboración interadministrativa INAP) de 25 mayo de 2012. Luego han circulado sucesivas versiones del Anteproyecto de Ley (13 de julio de 2012, 28 de enero de 2013 , 18 de febrero de 2013, 24 de mayo de 2013 y 22 de julio de 2013).

7 La ley ha sido objeto de diversos estudios y así por orden cronológico "La reforma de 2013 del régimen local español", Fundación Democracia y Gobierno Local, 2014, obra colectiva coordinada por Juan Alfonso Santa María Pastor, "La reforma del régimen jurídico de la administración local. El nuevo marco regulatorio a la luz de la ley de racionalización y sostenibilidad de la administración local”, obra colectiva coordinada por Juan Antonio Carrillo Donaire y Pilar Navarro Rodriguez, La ley-El Consultor, 2014, igualmente colectiva y dirigida por Tomás Quintana López, "La reforma del régimen local. Comentario a la ley 27/2013, de 27 de diciembre, de racionalización y sostenibilidad de la administración local", Tirant lo Blanch, 2014. Igualmente Lorenzo Mellado Ruiz, "Génesis y realidad de la ley 27/2013, de 27 de diciembre, de racionalización y Sostenibilidad de la administración local: ¿una nueva reforma local?”, CEMCl, 2014 , Manuel Medina Guerrero "La reforma del régimen local”, Tirant lo Blanch , 2014, Campos Daroca, José María, “La reforma de la Ley de bases de régimen local: Ley 27/2013, de 27 de diciembre", Bosch, 2014 y Cebrián Abellán, Manuel, “El régimen local tras la reforma de la Ley de racionalización y sostenibilidad”, Bosch -Wolters Kluwer, 2014.

8 Así lo ha señalado Luis Cosculluela Montaner en "Reforma de la administración local. Una oportunidad de modificar la planta local que no puede perderse”, págs. 11 a 19 de Revista española de derecho administrativo, Civitas- Thomson-Reuters, n 157 Enero-Marzo de 2013.

9 Sobre los efectos del Memorándum of understanding, puede consultarse a Gaspar Ariño Ortiz, y Miriam García "Vindicación y Reforma de las cajas de ahorro", Thomson-Civitas, 2013 págs. 174 a 184. 
del ejercicio de actividades económicas por parte de las EELL y así, el Preámbulo profundiza en los objetivos de la norma, señalando su deseo de favorecer la iniciativa económica privada, evitando intervenciones administrativas desproporcionadas, y su voluntad de limitar el uso a autorizaciones administrativas para iniciar una actividad económica, tan solo en casos en los que su necesidad y proporcionalidad queden claramente justificadas.

Así mismo, se suprimen monopolios municipales que venían heredados del pasado y que recaen sobre sectores económicos pujantes en la actualidad.

Esta determinación, junto al argumento igualmente esgrimido de racionalizar la estructura organizativa de la administración local, de acuerdo con los principios de eficiencia, estabilidad y sostenibilidad financiera, son las grandes líneas argumentales que inciden en la configuración de la iniciativa económica local, que venía siendo tradicionalmente utilizada en base a la redacción originaria de la LRBRL, conforme a la habilitación del artículo 128.2 de la Constitución; a través de las determinaciones del artículo 25 sobre prestación de cuántos servicios redundaran en beneficio de la comunidad local, del artículo 28 de las actividades complementarias a las competencias propias municipales, en el artículo 85 en cuanto a la forma de prestación de los servicios y especialmente el artículo 86 en cuanto la iniciativa económica, por parte de las Corporaciones Locales.

Así la nueva LRBRL, recoge en la redacción otorgada por el artículo $1^{\circ} .11$ de la LRSAL, una clara supresión del artículo 28, e igualmente en el artículo $1^{\circ}, 8$ de la indicada Ley 27/2013, otorga una nueva redacción del artículo 25 LRBRL, en relación con las competencias que impide esa libre prestación y ejercicio de competencias que redunden en la satisfacción de las necesidades y aspiraciones de la comunidad vecinal, puesto que el artículo 25.1, queda reformado en sentido a la prestación de gestión de intereses y en el ámbito de sus competencias, y por tanto solo el ámbito de sus competencias, eliminando esa cláusula genérica, o supeditándola, como más adelante comprobaremos, al objetivo o requisito previo de estabilidad presupuestaria.

En cuanto a los servicios se mantiene una distinción entre servicios obligatorios, (art.26) y los servicios que se presten en virtud de de competencias propias (art. 25).

Por otra parte, el artículo primero 21, de la Ley 27/2013 modifica el apartado 2, y suprime el apartado 3, del artículo 85, de la LRBRL. En ese sentido se introduce una priorización en las formas de gestión de los servicios públicos de carácter directo, puesto que en la gestión indirecta remite, como venía siendo habitual, a la legislación de contratos del sector público, en concreto al contrato de gestión de servicios públicos previsto por el TRLCSP 3/2011 de 14 de noviembre.

Esta variación pretende establecer una forma de gestión más sostenible y eficiente, de entre las cuatro fórmulas hasta ese momento existentes, recogiéndose que para el uso de las fórmulas de entidad pública empresarial local y sociedad mercantil local, (ahora con la denominación de capital público), unos requisitos previos para su elección frente a la entera libertad que la regulación anterior disponía para la citada elección.

Así, la primera variación sobre la redacción anterior de la LRBRL, es la denominación de las sociedades esto es, no siendo ya referido tan solo a las de capital íntegramente municipal, puesto que, con acierto, en la nueva redacción legal se permite las sociedades intermunicipales, (circunstancia esta que ya había previsto alguna norma sectorial, como por ejemplo, la de los canales locales para televisión digital terrestre), dicha fórmula de sociedades intermunicipales, y de otros entes locales; como por ejemplo, el capital de la diputación y municipios, o de mancomunidades, aunque esta circunstancia, con la prohibición de la disposición adicional novena de la LRSAL, parece poco probable, puesto que nos encontramos ante una sociedad que se debe considerar de segundo grado.

La segunda matización sobre la LRBRL, de la LRSAL, en estos supuestos de entidad pública empresarial, y sociedad mercantil local, es el deber de acreditarse mediante una memoria justificativa específica, esto es "ad hoc", elaborada al efecto sobre que dichas fórmulas resultan más sostenibles y eficientes que las formas dispuestas por la Ley de Gestión Administrativa, esto es, la gestión por la propia entidad local, y el Organismo Autónomo Local.

A los efectos de dicha elección, se deben tener en cuenta los criterios de rentabilidad económica y recuperación de la inversión, aunque no se especifica, (como se recogía en las diversas versiones de los anteproyectos), la necesidad de cumplimentar el cumplimiento de la prestación de los servicios mínimos, cuestión que apunta Del Guayo $^{10}$ y que incide en la cumplimentación de las actividades económicas de base administrativa. Por tanto, la LRSAL viene a establecer unos criterios en base a las condiciones de mercado de los clásicos supuestos, a justificar en el expediente sobre oportunidad y conveniencia, lo que independientemente de las opiniones sobre el fondo del asunto aporta mayor seguridad jurídica y menor margen de discrecionalidad.

10 Iñigo Del Guayo Castiella, op. cit. “Nuevo régimen jurídico de los servicios públicos locales, tras la reforma de la ley $27 / 2013$, de 27 de diciembre, de Racionalización y Sostenibilidad de la Administración Local”, págs. 490 a 499 de El consultor de los Juzgados y los Ayuntamientos, $\mathrm{n}^{\circ} 5$ 2014, 15 de marzo, y en concreto pág. 492. 
Además se debe hacer constar en el correspondiente expediente acreditativo una memoria justificativa, como ya se recogía en el TRRL, pero en este caso debe reflejarse el asesoramiento recibido, que además debe de elevarse al Pleno para su aprobación, debiéndose incluir en dicha memoria los informes sobre el coste del servicio"11, así como el apoyo técnico recibido, que deben ser publicitados.

Igualmente debe recabarse informe del Interventor Local, el cual en este debe valorar la sostenibilidad financiera de las propuestas planteadas, de conformidad con lo establecido en el artículo $4^{\circ}$ de la Ley Orgánica 2/2012, de 27 de abril, de Estabilidad Presupuestaria y Sostenibilidad Financiera, que recordemos establece:

\section{Artículo 4 Principio de sostenibilidad financiera}

1. Las actuaciones de las Administraciones Públicas y demás sujetos comprendidos en el ámbito de aplicación de esta Ley estarán sujetas al principio de sostenibilidad financiera.

2. Se entenderá por sostenibilidad financiera la capacidad para financiar compromisos de gasto presentes y futuros dentro de los límites de déficit, deuda pública y morosidad de deuda comercial conforme a lo establecido en esta Ley, la normativa sobre morosidad y en la normativa europea.

Se entiende que existe sostenibilidad de la deuda comercial, cuando el periodo medio de pago a los proveedores no supere el plazo máximo previsto en la normativa sobre morosidad.

En ese sentido la limitación al principio del cumplimiento de la estabilidad presupuestaria, lo será, (lo cual tiene una importancia cardinal que condiciona todo el ejercicio de actividades y funciones "no principales " por las entidades locales), a la verificación de las tres reglas, déficit, deuda y pago a proveedores, por lo que la Ley Orgánica 2/2012 de 27 de abril, de Estabilidad Presupuestaria y Sostenibilidad Financiera, realiza un desarrollo de la previsión constitucional, más rigorista pero muy loable técnicamente, puesto que se debería pensar en un Ayuntamiento sin deuda, ni incluso déficit que pagara a sus proveedores a seis meses, pero que aprobara la creación de una nueva empresa municipal.

Existe otra limitación para el ejercicio de actividades mediante gestión de servicios con fórmulas de naturaleza empresarial, ya sean los EPES, o las Sociedades Mercantiles Locales de capital social de titularidad pública, que es el límite tradicional antiguamente previsto en el artículo 85.3, y que ahora se recoge en el propio 85.2, de que la forma de gestión por la cual se opte, debe de respetar el ejercicio de autoridad reservado a funcionarios, puesto que se remite de forma expresa al artículo $9^{\circ}$ de la Ley $7 / 2007$ de 12 de abril, por la cual se aprueba el Estatuto Básico del Empleado Público y no por cierto a la nueva redacción del art 92 LRBRL, que es mucho más restrictiva, al reservar a funcionarios no solo el ejercicio de potestades, sino también las de carácter indirecto, y la salvaguarda del interés general. Por lo tanto, todos aquellos aspectos que supongan el ejercicio o salvaguarda de potestades, y por supuesto el ejercicio de autoridad, quedarán reservadas a estas formas.

Es sustancialmente una concepción más amplia, aunque no una radicalmente diferente de la anteriormente prevista en la ley, que prohibía el ejercicio de actividades mediante formas societarias a aquellas que implicaban el ejercicio de autoridad, y ahora se amplia para las que impliquen el ejercicio de potestades, circunstancia ésta que técnicamente puede establecer algún matiz, pero debe recordarse que pocas potestades se ejercen en un ámbito empresarial.

Así, este matiz, supone un cambio radical en la concepción de las entidades públicas empresariales, estudiadas por Montoya Martín'12, puesto que la existencia de dichas potestades, sí estaba prevista en la redacción original del artículo 85, tras la ley 57/2013 de 16 de diciembre, de Modernización del Gobierno Local, para las entidades públicas empresariales, que se convirtieron en auténticos elementos duales, cuestión esta, que al no permitirse el ejercicio de potestades de esa forma sibilina, o no directamente expresada, supone la limitación de las EPES al ejercicio de actividades mercantiles, no pudiendo ejercer potestades, al menos en el ámbito local. Circunstancia ésta que no ha venido acompañada de una reforma de la LOFAGE, la Ley de Organización y Funcionamiento de la Administración General del Estado 6/1997. En ese sentido, si se sigue permitiendo el ejercicio de potestades para

11 Con respecto al coste de los servicios se debe tener en cuenta la Orden HAP/2075/2014, de 6 de noviembre, por la que se establecen los criterios de cálculo del coste efectivo de los servicios prestados por las entidades locales.

12 Encarnación Montoya Martín, “Las entidades públicas empresariales locales en el ámbito local”, lustel, 2006, también nosotros nos hemos ocupado de la materia en: “Las Entidades Públicas Empresariales Locales”, Fernando García Rubio, Revista de estudios locales. Cunal, №. 117, 2009, págs. 24-43 y" Los entes públicos empresariales" Fernando García Rubio dentro de la obra colectiva "Estudio sobre empresas públicas", coord. por Fernando García Rubio, Dykinson 2011, págs. 73-92. 
las EPES de ámbito Estatal, norma recuérdese a la que la LRBRL, remitía y que el constitucional en la STC $103 / 2013$ ha considerado acorde con la Carta Magna. Por tanto, tras la reforma cabría plantearse si tiene algún sentido la existencia de EPE'S locales, o al menos la imprescindible precisión de la cuestión apuntada.

Finalmente, dentro de estas consideraciones generales sobre el ámbito de la reforma local de 2013 sobre el ejercicio de actividades económicas, debemos indicar que el artículo $1^{\circ}$, veintitrés de la Ley de Racionalización, establece una nueva redacción del artículo 86 LRBRL, que es el núcleo esencial de la capacidad del ejercicio de libertad e iniciativa pública para el desarrollo de actividades económicas en el ámbito local; el cual supone una limitación de dicha iniciativa pública, eso sí, condicionándola al cumplimiento del objetivo de estabilidad presupuestaria y sostenibilidad financiera del ejercicio de sus competencias. Hay quien, como Rivero Ysern ${ }^{13}$, ha visto ocultas intenciones al suprimir la referencia concreta al art. 128 de la Constitución.

\section{LA INICIATIVA ECONÓMICA LOCAL Y LA ESTABILIDAD PRESUPUESTARIA, DETERMINACIONES CONSTITUCIONALES}

Por tanto, en la práctica la nueva redacción de la LRSAL, supone una supeditación de la habilitación del artículo 128 de la Constitución, a la redacción del artículo 135 de la Constitución, ambos recogidos en el Titulo Séptimo de la Carta Magna sobre Economía y Hacienda, circunstancia ésta que queda plasmada en el ámbito concreto local, en este nuevo artículo 86 LRBRL.

Así ya, analizadas con carácter general las modificaciones en materia de iniciativa económica de las entidades locales previstas por la LRSAL, debemos tener en cuenta que las determinaciones históricas y Constitucionales de dicha actuación económica de la Administración en general y de la Administración Local en particular.

El citado principio de iniciativa pública económica, tal y como destaca Sebastián Martín Retortillo ${ }^{14}$, es uno de los principios fundamentales de nuestra Constitución Económica, lo que es reconocido como tal de forma unánime por toda la doctrina, por lo que nos encontramos ante un sistema económico dual, en que el que concurren conjuntamente agentes privados, conforme a la libertad de empresa del artículo 38, (que pretende favorecer de forma indirecta la reforma local, en cuanto a la existencia de los agentes privados), y agentes públicos a la vista del reconocimiento de la iniciativa pública económica por el art 128.2 CE, en las actividades de mercado.

Eso sí, en cuanto al ejercicio de dichas actividades económicas, los agentes públicos y privados se rigen por un principio de rigurosa igualdad, salvo los supuestos de monopolio y reserva exclusiva, previstos igualmente en el artículo 86.2 LRBRL, y que se derivan también del artículo 128.2 (segundo inciso) de la propia Constitución, aunque debemos recordar, tal y como acertadamente apunta Ariño ${ }^{15}$, que la reserva no tiene por qué suponer una gestión empresarial por parte de las AAPP, sino que existe un ámbito para la gestión por particulares a través de las concesiones u otros títulos jurídicos para la explotación.

Así, ese reconocimiento faculta a los poderes públicos como agentes económicos productores de bienes y servicios, y tal y como indica el citado Martín Retortillo ${ }^{16}$, no con carácter excepcional o subsidiario, si no, una línea de marcada normalidad, puesto que a juicio del citado autor no hay restricción ni título Constitucional que jurídicamente obstaculice que el sector público pueda intervenir en las diferentes actividades económicas, y ello cualquiera que sea la amplitud de eficacia con que cada una de ellas pueda operar el sector privado.

Dicha cuestión, irrefutable en su momento, debe en nuestra opinión, lógicamente ser analizada ahora al amparo de la determinación Constitucional del artículo 135 de la Carta Magna.

Esta determinación originaria de la CE, desde un punto de vista Constitucional, supuso una variación del principio de subsidiariedad, principio que está latente en la voluntad de la reforma local, aunque no se expresa de forma explicita. Así al respecto existe numerosa bibliografía, que en la opinión mayoritaria recoge Fernández Farreres ${ }^{17}$, y en la minoritaria Ariño Ortiz ${ }^{18}$.

En el ámbito local, tal y como acertadamente señala Sosa Wagner ${ }^{19}$, cabe distinguirse dos tipos de ejercicios de actividades económicas, circunstancia que por la nueva redacción de la LRBRL, no se desvirtúa.

13 Jose Luis Rivero Ysern, “Manual de derecho local”, séptima edición, Cívitas-Thomson. 2015, en concreto pág. 481.

14 Sebastián Martín Retortillo, Derecho Administrativo Económico I, Editorial, la Ley 1988, pág. 93-94

15 Gaspar Ariño Ortiz, “Empresa pública, empresa privada, empresa de interés general”, Thomson-Aranzadi 2007, pág. 75.

16 Sebastián Martín Retortillo, op cit., pág. 95.

17 Germán Fernández Farreres, “Reflexión sobre el principio de Subsidiariedad y la Administración Económica”, dentro de la obra colectiva Estudios de Derecho Público Económico, libro homenaje al Profesor, Sebastián Martín Retortillo, Civitas 2003.

18 Gaspar Ariño Ortiz, “La Iniciativa Pública en la Constitución. Delimitación del sector público en control de su expansión”, Revista de administración pública $n^{\circ} 88$, págs. 55 y ss.

19 Francisco Sosa Wagner, “Manual de Derecho Local”, Tecnos, 1996, tercera edición, págs. 177-178. 
Por un lado aquél ejercicio de actividad económica, que en palabras del citado autor supone que se somete la administración al ejercicio de las prestaciones como un sujeto más, y por otra parte, cuando esto se realice en base a la existencia a la reserva del sector público de una actividad o servicio, que son las actividades expresamente recogidas ahora en el artículo 86.2 de la LRBRL, y en su momento y desde el año 1985 hasta el 2013, en el apartado 3 de dicha norma legal.

El primero de los casos supone la igualdad entre iniciativa pública y privada de carácter empresarial, que aunque tienen fundamentos Constitucionales distintos, como ya hemos indicado, de ambos no puede deducirse la prevalencia de ninguna sobre la otra, si no, tal y como afirma Fernando Sainz Moreno ${ }^{20}$, que ambas lógicamente tienen una función esencial que delimita su contenido, o lo que en palabras del citado autor no es lo mismo, y la subordina a la consecución al bien común del interés general.

Ello se basa en concreto en la libertad económica, que puede tener su origen en la ley Allarde, Ley 2 de17 de marzo de 1791, en la cual se diferenciaba y reconocía la libertad de trabajo, y la libertad de comercio e industria.

Bien, dejando este marco general sentado, debemos plantearnos una serie de reflexiones sobre el ya apuntado, principio de estabilidad presupuestaria y falta de déficit estructural, al amparo del artículo 135 de la Constitución, en relación con la iniciativa empresarial de la Administración.

Así, en primer lugar debemos recordar, concordando en este aspecto con el ya citado Sainz Moreno ${ }^{21}$, que el Estado en sí mismo no es una empresa, no tiene vocación de generar beneficios, como toda empresa, y en ese aspecto tampoco los ciudadanos a los que presta sus servicios, o entrega sus bienes son clientes, puesto que recuérdese la máxima de un conocidísimo Centro Comercial, el cliente siempre tiene razón y no en el ámbito de las relaciones entre las Administraciones y los ciudadanos, teniendo como tal el término adecuado de la LRJAPC, y no el anticuado del administrado, y así los ciudadanos son sujetos de derechos y deberes, puesto que están sometidos a las potestades, y no siempre tienen razón.

Partiendo de esa circunstancia, podríamos plantearnos la diferenciación entre empresa pública y empresa privada, circunstancia esta que no concurre al menos en cuanto a la forma jurídica, las sociedades mercantiles públicas tienen estructura y un régimen jurídico idéntico a las privadas en relación que se someten a la misma legislación, fundamentalmente al Texto Refundido de la Ley de Sociedades de Capital, en menor medida al código de comercio y en algún otros supuestos a las legislaciones correspondientes.

Es cierto que existen algunas modulaciones ya reconocidas por el Tribunal Constitucional, con respecto al sometimiento a las reglas de control público y de gasto, así como, a su incorporación en el concepto de "Sector Público", con las lógicas vinculaciones de dación de cuentas al Tribunal de Cuentas, y supervisión de este alto órgano Constitucional de su actividad, de sujeción por su capital y naturaleza pública, a unas reglas de contratación diferenciadas, pero no idénticas en todo momento al de las entidades administrativas, derivadas de la legislación de contratos del sector público, etc., pero en sentido estricto son sociedades mercantiles, simplemente las diferencia el dueño de esa sociedad mercantil, que por carácter general al ser el Estado Español signatario del Tratado de la Unión Europea, no puede tener un privilegio en forma de ayuda al Estado, conforme a la transferencia corriente que se hacia para enjugar los déficits de las correspondientes empresas.

Por tanto, si existe una actividad empresarial del sector público esta debe de ajustarse a las reglas de la libre competencia y falta de ayuda, esto es, competir en posición de igualdad, con el resto de las empresas, al menos, por lo que respecta a la primera de las modalidades de sociedad mercantil, o iniciativa pública local que hemos hecho referencia, la de la libre prestación de servicios o producción de bienes.

En ese sentido debemos recordar que a la hora de la intervención en la economía deben de respetarse una serie de principios constitucionales para garantizar no sólo la cláusula del Estado social, sino también la cláusula del Estado de Derecho, aunque tal y como recordaba Muñoz Machado ${ }^{22}$ existen derivados del propio texto constitucional, una serie de límites conforme a la propia iniciativa pública en la actividad económica del art. 128.2, de la acción del derecho en base al 53.2 y por la propia limitación del mercado recogida en las Sentencias del Tribunal Constitucional 83/1984 y 123/1991 como marco obligado a la libertad de empresa, tal y como describe la STC 88/1986 que implica un parámetro en el que puede moverse los poderes constituidos al adoptar medidas que inciden sobre el sistema económico de nuestra sociedad.

20 Fernando Sainz Moreno, “La Intervención Administrativa en la Actividad Empresarial Pública”, págs. 151 a 162 , de la obra colectiva, dirigida por Mariano Baena del Alcázar, La Reforma del Estado y de la Administración Española, INAP, 2013, y en concreto pág. 157.

21 Fernando Sainz Moreno, op. cit., pág.158.

22 Santiago Muñoz Machado. “Los límites constitucionales de la libertad de empresa”, pág. 139 a 163, de Estudios de Derecho Público Económico. Libro homenaje al Profesor D. Sebastián Miguel Retortillo, Cívitas 2003. 
La Reforma Local, en este aspecto, ha supuesto una cierta clarificación, aunque no definitiva, en nuestra opinión, de la diferenciación entre actividad económica, servicio, y actividad reservada, que la redacción originaria del artículo 86 LRBRL, mezclaba o confundía, pese a su diferenciación conceptual y su diferente fundamento Constitucional. Así podemos distinguir entre la capacidad de iniciativa económica que tiene toda entidad local en el momento actual supeditado al cumplimiento previo de la estabilidad presupuestaria para el ejercicio de actividades económicas con carácter libre en el ámbito del mercado y supeditación a las reglas de este, sin posibilidad de ayudas de carácter oficial a dicha prestación de la actividad económica.

La vinculación de la prohibición de ayudas es evidente al amparo de las determinaciones del tratado de funcionamiento de la Unión Europea, y en ese sentido, dicha prohibición debe nuevamente vincularse al concepto nuevo de la existencia de servicios públicos, diferenciados de los servicios afectados por la directiva Bolkenstein.

En esa línea, es paradigmático el dictamen del comité Europeo de las regiones sobre los servicios públicos del año 1997.

Esta cuestión debe de ser analizada diferenciadamente para aquellas materias en que se ejerce actividad como sector público en materias reservadas, ahora por el artículo 86.2 en virtud de la habilitación Constitucional del artículo 128.2, segundo inciso, correspondiente.

Así es, tal y como indica Hurtado López ${ }^{23}$, que la interrelación de un ejercicio de una actividad económica con la legislación de estabilidad presupuestaria y sostenibilidad financiera, tiene una doble manifestación, por una parte, hacia el interior, en tanto esa actividad no puede, a juicio del indicado autor, implicar incumplimientos de aquella normativa, y hacia el exterior, en tanto no se podrá asumir sin con el ejercicio de competencias que les son propias no existen garantías de cumplimiento del objetivo de estabilidad presupuestaria ,ni de sostenibilidad financiera.

Siendo esta última circunstancia asociada a los límites de endeudamiento de las entidades locales, límites que vienen fijados por los artículos 51 y 53, del Texto Refundido de la ley Reguladora de las Haciendas Locales, aprobada por Real Decreto Legislativo 2/2004, de 5 de marzo, en la redacción otorgada por la Disposición Final Trigésimo Primera, de la ley de Presupuestos Generales del Estado para 2013, 17/2012 de 27 de diciembre.

Por tanto, con carácter general el ejercicio de la iniciativa económica, que no queda eliminada, si no que se limita y subordina a la estabilidad presupuestaria, debe de hacerse en el ámbito de las competencias propias de las diferentes Entidades Locales, y por tanto en el de los municipios del artículo 25, y en el de las Diputaciones en el del artículo 36 ambos de la LRBRL, estándose a la legislación Autonómica, en el caso que hubiese modulaciones, para las competencias del resto de las entidades locales previstas en la citada legislación básica estatal.

Cabe plantearnos si esa supeditación lo es solo para el déficit o también para las otras 2 reglas del art $4^{\circ}$ LOEPSF.

En ese sentido, y pese a la escasa precisión que se hace en el artículo 86 LRBRL, tras la redacción operada por la LRSAL, lo cierto es que, parece evidente que del conjunto sistemático de la ley, esto es por ejemplo, la excepciones al efecto inmediato de aplicación de la rebaja salarial de los altos cargos, o del número de eventuales, y de la remisión al artículo cuarto, de la ley orgánica de estabilidad presupuestaria y sostenibilidad financiera, que se hace igualmente por la ley en relación con la prestación de servicios, y el ejercicio de competencias, deberemos interpretar en buena lógica que el cumplimiento lo es de las tres ya sabidas reglas: déficit estructural, deuda pública, y pago a proveedores.

En cualquier caso, los municipios que se encuentran afectados por un plan de ajuste, o por un plan económico financiero, en virtud en lo dispuesto en el nuevo artículo 116 bis, de la LRBRL, parecen lógicamente afectados por las tres reglas de una manera absoluta, puesto que no podrán ejercer dicha iniciativa económica, siendo incongruente, una interpretación en sentido contrario, puesto que si deben desaparecer las formas societarias de ejercicio de actividades económicas que no fueran rentables ¿puedan ser sustituidas éstas por el propio ejercicio en nuevas actividades por parte de la entidad local?. Sería un contrasentido en el conjunto del sistema.

Como ya hemos señalado, el verdadero nudo gordiano de la determinación del ejercicio de la libre iniciativa económica local, capitidisminuida, o supeditada al equilibrio presupuestario, lo es por la contraposición del artículo 128 de la Constitución al nuevo artículo 135, tras la modificación Constitucional operada en septiembre de 2011.

23 Gabriel Hurtado López, "El rediseño y redimensionamiento del sector público económico local," págs. 307 a 337, de obra colectiva “La reforma de 2013 del régimen local español”, Fundación Democracia y Gobierno Local, 2014, coordinador, Juan Alfonso Santa María Pastor. 
En ese sentido debemos destacar con María Luisa Esteve ${ }^{24}$,que se plantea que dicha limitación de iniciativa económica supone en mayor o menor medida, una limitación de la autonomía local del artículo 140 de la Constitución, circunstancia esta que se vincula a la interpretación que del principio de autonomía local realiza el Tribunal Constitucional de la autonomía financiera, tal y como se recoge la STC 63/1986, de 21 de mayo, puesto que ésta forma parte "de la autonomía para gestión de sus propios intereses, de acuerdo con el artículo 137 de la Constitución" ${ }^{25}$, recogiéndose igualmente una fundamentación en el sentido de dicha amplia concepción de la autonomía financiera local en la Sentencia del Tribunal Constitucional 221/1992, de 11 de diciembre, en el que la autonomía territorial posee también una determinación en el terreno tributario, pues estos entes locales han de contar con tributos propios, y sobre los mismos, deberá la ley reconocer una intervención en el establecimiento de su exigencia conforme a los artículos 140 y 133 de la Constitución (STC 221/1992, de 11 de diciembre, fundamento jurídico $8^{\circ}$ ).

¿Esa autonomía financiera supone una autonomía de déficit, y por tanto de desequilibrio presupuestario?, entendemos claramente que no, no solo por la nueva redacción de la Constitución, sino por el hecho de la interpretación sistemática de ésta, en el conjunto de nuestro ordenamiento jurídico.

En nuestra opinión entendemos que dicha cuestión ya esta claramente resuelta por el Tribunal Constitucional en su Sentencia 134/2011, de 20 de julio, en cuyo fundamento jurídico 14, se recoge de forma expresa, en esta caso en relación, no con la actual Ley de estabilidad presupuestaria como es lógico, sino con la Ley 18/2001, la plena aplicabilidad a los entes locales de la competencia estatal, sobre los presupuestos del sector público, tanto estatal, autonómicos, como locales, no quebrantándose su autonomía política porque se establezca un cumplimiento de la estabilidad presupuestaria, recogiéndose por tanto de forma expresa " que en suma el derecho de intervenir de los entes locales en los asuntos que les atañen " ( STC 214/1989, fundamento jurídico 1), no se pone en cuestión por el hecho de que se someta a las previsiones Constitucionales entre las que figura el establecimiento por el estado de la ordenación, ex artículo 149.1.13 ${ }^{a}$ de los Presupuestos de dichos entes."

En dicha línea, se han pronunciado las Sentencias del Tribunal Constitucional 185, 186, 187, 188, 189/2011, de 23 de noviembre, y las 195, 196 y 197/2011 de 13 de diciembre, todas sobre la misma materia, por tanto, no puede entenderse como inconstitucionalidad, el someter la capacidad presupuestaria local al cumplimiento del principio de estabilidad presupuestaria.

Ahora bien, la limitación en la capacidad de ejercicio de la actividad económica no se puede deslindar de las medidas de control o redimensionamiento, en palabras del legislador, del sector público local, en tanto en cuanto, tal y como afirma Díaz Lema ${ }^{26}$, donde el texto (en aquel momento referido al anteproyecto, pero que el texto final no ha cambiado sustancialmente), establece desde diversas medidas de contención, desde la prohibición a las entidades locales de constituir entidades instrumentales, durante la vigencia de su plan económico financiero ,o de su plan de ajuste, hasta imponer planes de corrección de desequilibrios financieros a aquellas entidades que se encuentren en situación deficitaria.

En dicha línea, debemos destacar en buena medida, que aunque evidentemente la actividad económica se pueda ejercer directamente por la administración, la limitación para ejercer mediante entidades instrumentales es racional y hasta necesaria dada la falta de contención y mesura de algunas autoridades. En cualquier caso, como parece lógico, existe una limitación, como más adelante abordaremos, de carácter general para aquellas administraciones que estén incursas en déficit en relación con ejercicio de actividades económicas. Eso es lo que podemos resumir que de "zapatero a tus zapatos", esto es una predilección y consecuente opción que realiza el legislador sobre la capacidad autónoma de la entidad local de dónde destinar, en primera instancia, sus recursos y capacidades.

Visto lo anteriormente expuesto, la rápida interpretación de la vinculación del artículo 135 de la Constitución sobre el principio de estabilidad presupuestaria, sobre el 128.2 de la actividad económica pública, no debe de desprenderse de nuestra incorporación a la Unión Europea, puesto que si bien es cierto, tal y como recuerda Esteve $\mathrm{Pardo}^{27}$, en el concreto momento de que se aprobó la reforma de la Constitución Española, no existía ninguna norma europea que vinculase la restricción del déficit público al déficit estructural, puesto que el artículo 126 del Tratado de funcionamiento de la Unión Europea, vinculaba en relación con el déficit cíclico.

24 María Luisa Esteve Pardo, “El impacto del principio de estabilidad presupuestaria sobre los gobiernos locales”, págs. 153 a 172 de anuario de gobierno local 2012, obra colectiva dirigida por Tomás Font i Llovet, y Alfredo Galán Galán, "Racionalización y sostenibilidad de la administración local: ¿Es esta la reforma?”, Fundación Democracia de Gobierno Local, Instituto de Derecho Público, mayo 2013.

25 Tal y como se refleja de forma expresa en el fundamento jurídico $4^{\circ}$ de la citada Sentencia 63/1986, de 21 de mayo, que trae a colación María Luisa Esteve Pardo en op. cit., pág. 157.

26 Jose Manuel Díaz Lema, “El anteproyecto de ley de Racionalización y Sostenibilidad de la administración local: ¿Cambio de rumbo en la administración local española?”, págs. 47 a 91 de op. cit. Anuario del 2012, y en concreto pág. 67.

27 María Luisa Esteve Pardo, op. cit. pág. 165 
Sí es cierto que en la actualidad la redacción del artículo 135.2 de la Constitución, es en el que se recoge, ya el artículo 3.1 en su letra b), del Tratado de estabilidad cooperación y gobernanza de la Unión económica y monetaria, que establece de forma expresa: “ b) la norma establecida en la letra a) se considerará respetada si el saldo estructural anual de las administraciones públicas alcanza el objetivo nacional específico a medio plazo, definido en el pacto de estabilidad y crecimiento revisado, con un límite inferior de déficit estructural del 0,5\%, del producto interior bruto a precio sobre mercado".

En ese sentido, ese tratado internacional lógicamente vincula al Estado Español en todos sus términos, y por tanto, a toda la organización territorial del Estado, teniendo por Estado las entidades integrantes de la organización del artículo 137 de la Constitución, y por tanto, las entidades locales.

En igual línea, debemos destacar el denominado SIX PACK, compuesto por cinco reglamentos y una directiva, que entró en vigor el 13 de diciembre de 2011, el Reglamento n 1175/2011, del Parlamento Europeo y del Consejo , de 16 de noviembre de 2011 por el que se modifica el Reglamento $n^{\circ} 1466 / 97$, del Consejo, relativo al reforzamiento del supervisor de las situaciones presupuestarias, y a la supervisión y coordinación de las políticas económicas, el reglamento 1177/2011, del Consejo de 8 de noviembre de 2011, por el que se modifica el Reglamento $n^{\circ} 1467 / 97$, relativo a la aceleración y clarificación del procedimiento de déficit excesivo, el reglamento $n^{\circ}$ 1173/2011, del Parlamento Europeo y del Consejo, de 6 de noviembre de 2011, sobre la ejecución efectiva de la supervisión presupuestaria en la zona del euro, el reglamento $n^{\circ}$ 1176/2011, del Parlamento Europeo y del Consejo, de 16 de noviembre de 2011, relativo a la prevención y corrección de los desequilibrios macroeconómicos, y el reglamento $n^{\circ}$ 1174/2011, del Parlamento Europeo y del Consejo, de 16 de noviembre de 2011, relativo a las medidas de ejecución destinadas a corregir los desequilibrios macroeconómicos excesivos en la zona del euro, finalmente el citado paquete se complementa con la directiva $n^{\circ}$ 2011/85/UE, del Consejo, de 8 de noviembre de 2011, sobre requisitos aplicables a los marcos presupuestarios de los estados miembros.

Por tanto al amparo de la habilitación Constitucional, de cesión de soberanía a la Unión Europea prevista por artículo 96.2 de la Carta Magna, así como el propio tratado de funcionamiento de la Unión Europea, parece muy difícil sostener la inconstitucionalidad de las determinaciones de la ley de Racionalización sobre la supeditación del gasto en general, y en concreto, en este caso la actividad económica municipal, al cumplimiento de las reglas de gasto y déficit público, por lo menos en nuestra opinión.

Sentado esto, podremos destacar dos primeras cuestiones en relación con la materia que nos ocupa con respecto a la constitucionalidad de la norma, esto es de la nueva redacción del art 86 LRBRL, tras la Ley de racionalización.

La primera de las cuestiones es si la limitación de la actividad económica y su ejercicio por parte de cada entidad local al cumplimiento de un criterio previo de estabilidad presupuestaria, incide o no, en su ámbito de autonomía; y en ese sentido ningunea por tanto el artículo 140 de la Constitución. Circunstancia que entendemos que conforme a las argumentaciones relatadas y a la constitucionalización del principio de estabilidad del artículo 135, en relación con el lógico principio del interés general del artículo 103.1, válido para todas las administraciones, recuérdese, junto igualmente a la correcta asignación de los recursos públicos, en este caso escasos y limitados a los ingresos, que recoge el artículo 31 de la Constitución.

En estos supuestos, si no existe control de oportunidad, entendemos que la regulación es plenamente Constitucional por lo que partiendo de los requisitos procedimentales previstos en el artículo 86.1, de la memoria, parece necesario, en ese sentido, dado el reconocimiento por nuestra Constitución de la economía de mercado, lo que implica cuando se ejercitarán estas actividades de contenido económico por la administración local la necesidad de justificar el cumplimiento de esas reglas del mercado, esto es la innecesariedad de que recursos públicos en administraciones deficitarias vayan a compensar gastos generados por actividades propias del mercado, que deben de supeditarse a la falta de ayuda expresamente prevista por el Tratado de funcionamiento de la Unión Europea.

Como segunda cuestión, desde ese punto de vista, competencial versus constitucional, de la nueva redacción del artículo 86 LRBRL, operado por la LRSAL, tenemos la de la capacidad del legislador básico estatal, para establecer esta limitación para las entidades locales y en su caso, para recoger un cauce procesal determinado para el ejercicio de dichas actividades.

En ese sentido, debemos destacar dos grandes bloques, de Estatutos de autonomía en relación con dicha cuestión, los estatutos de autonomía “revisados" en el periodo 2006-2010, y que incorporan con carácter general la competencia exclusiva de la Comunidad Autónoma en materia de régimen local, y por tanto, una capacidad más intensa sobre las entidades locales, que en buena medida han supuesto el reconocimiento de competencias de tutela financiera por parte de la Comunidad Autónoma sobre las entidades locales, y que la LRSAL, recoge al establecer en los diversos procedimientos de cumplimiento de estabilidad presupuestaria la remisión a la 
administración con competencias en materia de tutela financiera y en su caso al Ministerio de Economía y Hacienda.

Y por otra parte, las Comunidades Autónomas con Estatuto, en el cual se reconoce simplemente competencias para el desarrollo de la legislación básica de régimen local y las competencias que el Estado transfiera a las Comunidades Autónomas en materia de régimen local.

Igualmente, esa capacidad o iniciativa pública de carácter económico que debe quedar claramente diferenciada, y se debe supeditar a dos ámbitos, por un lado un ámbito previo de estudio y viabilidad de la propia iniciativa económica en el marco de la estabilidad presupuestaria, y la racionalidad de la prestación de actividades económicas que pese a la habilitación general que hace el constituyente, no puede ser muy racionales en manos públicas, al menos por la incongruencia en relación con la competitividad por las diferencias entre los sistemas de empleo público y privado.

Aunque lógicamente esto es muy discutible y sometido a las correspondientes opciones políticas, puesto que hay ideologías que propugnan la propiedad pública de los medios de producción y por tanto cualquier actividad económica debería estar en manos públicas. Pero que esta cuestión parece superada en el marco de nuestro ordenamiento jurídico por la propia Constitución, y nuestra incorporación en la Unión Europea, y por otra parte las capacidades de ordenación de los servicios de todo tipo, y en este tema debemos recordar el concepto amplio de servicio que recoge, no solo nuestra legislación de régimen local, sino el conjunto de la legislación administrativa y por ende la jurisprudencia del Tribunal Supremo.

Así debemos recordar en ese aspecto la Sentencia del Tribunal Supremo, de 1 de febrero de 2002, (Art. 1590), que entiende por servicios públicos "cuantos tienden a la consecución de los fines señalados como de la competencia de las entidades locales", estableciendo una equivalencia entre competencia y servicio, en cuanto éste corresponde a las fórmulas y actuaciones que realiza la administración para llevar a cabo la competencia.

\section{LA NATURALEZA JURÍDICA DE LA INICIATIVA ECONÓMICA ADMINISTRATIVA EN GENERAL Y LOCAL EN PARTICULAR. ALGUNAS MATIZACIONES}

Desde la expresa previsión del art 128.2 de la Carta Magna se ha teorizado mucho sobre la naturaleza de la iniciativa económica pública, como recuerda Tena Piazuelo ${ }^{28}$.

Ahora bien , tal y como hemos apuntado anteriormente esa iniciativa ya desde la base del art 128.2 CE tiene dos vertientes muy diferenciadas, las actividades con, o sin reserva monopolística a favor del sector público.

En ese sentido, por tanto, parece evidente, el plano estricto de igualdad en el ejercicio de actividades económicas que no se reserven al sector público y excluyan por tanto al privado entre la iniciativa pública, e iniciativa privada, igualdad que debe interpretarse no solo en la capacidad que tiene la administración para prestar actividades económicas sin ninguna subsidiariedad del sector privado, por ejemplo, en materia de aerobic, tal y como destaca la sentencia del Tribunal Supremo, de 20 de junio de 2006, sino también, en la vertiente de imposibilidad al ser igual que el privado, de que existan ayudas directas, o indirectas por parte de la Administración, esto es, de los recursos públicos presupuestarios destinados a ese ejercicio de la actividad económica.

Estas dos premisas se derivan de los ya apuntados principios de libertad de empresa recogidos en el art. 38 de la Carta Magna, y del comunitario de prohibición de ayudas de estado, que posteriormente se analizarán.

Ahora bien, ese plano de igualdad en el ejercicio de actividades económicas no reservadas, puede parecer incompatible con la prevalencia y naturaleza del ejercicio de potestades públicas, tal y como por contra ha mantenido Montoya Martin ${ }^{29}$, aunque solo sea por la necesidad que la LRSAL acentúa en este campo, tal y como se desprende de la nueva redacción del art 85 LRBRL, del ejercicio de estas a través únicamente de funcionarios.

Esta cuestión sobre la reserva de funcionario para ejercicio de potestades públicas, que hace el art. $9^{\circ}$ del Ley 7/2007, de 12 de abril del Estatuto Básico del Empleado Público y que el nuevo art 92.3 LRBRL acentúa en el ámbito local, hace reflexionar sobre dicho concepto, (el de ejercicio de potestades), y así a título de ejemplo debemos indicar siguiendo a Blanquer Criado $^{30}$, que las funciones públicas se realizan mediante el uso de potestades unilaterales de carácter exorbitantes que se ejercen en régimen de autotutela y sin previa intervención judicial. Así la indicada Montoya entiende que el ejercicio de la iniciativa económica por las AAPP es una potestad en

28 Vitelio M Tena Piazuelo, “La empresa pública local: Aspectos jurídico formales de la gestión municipal de intereses económicos mediante sociedad anónima” Revista de estudios de la administración local n²55/256, 1992 , págs. 701 a 730 y en concreto págs. $703-704$.INAP.

29 Encarnación Montoya Martín, "Título II. Los servicios y la iniciativa económicas locales”, dentro del libro colectivo Derecho local de Andalucía: la Ley 5/2010, de 11 de Junio de Autonomía Local de Andalucía, coord. por Encarnación Montoya Martín y Severiano Fernández Ramos; José Luis Rivero Ysern (director.), 2012, págs. 157-202.

30 David Blanquer Criado “Derecho Administrativo” Tomo II. Tirant Lo Blanch. Valencia 2010, pág. 385 a 386. 
si misma. No obstante, tal y como recuerda Cosculluela ${ }^{31}$ según la definición de Santi Romano: Las Potestades Administrativas son el poder jurídico para imponer decisiones a otros sujetos y para el cumplimiento de una finalidad determinada. Se trata, por tanto, de una situación jurídica activa en virtud de la cual su titular puede exigir o, incluso, imponer determinados comportamientos a otros sujetos de Derecho. En este sentido participa de rasgos comunes al derecho subjetivo. Debe recordarse que las potestades son los medios formales, o las herramientas jurídicas que permiten a la administración pública satisfacer el interés general, y para alcanzar ese objetivo puede ser necesario condicionar o forzar el comportamiento de los ciudadanos.

La titularidad de las potestades es un signo de la supremacía que el ordenamiento jurídico confiere a algunas personas e instituciones, (en el caso que nos interesa a un Ayuntamiento u entidad local), y el correlativo sometimiento de quien están sujetos a su ejercicio (los ciudadanos en un contexto que aquí se describe).

En el marco constitucional de un estado social y democrático de derecho, cuando implica el ejercicio de la fuerza o de la violencia legítima, o de supremacías genéricas el poder de la administración pública debe tener fundamento jurídico o normativo; lo mismo ocurre cuando el poder de la administración se emplea para limitar o restringir los derechos y libertades de los ciudadanos.

Para el uso de las prerrogativas de poder que exige el ejercicio de funciones públicas, es necesario que la administración esté autorizada o habilitada por los representantes parlamentarios de los ciudadanos, esto es la configuración y creación de potestades esta sometido al principio de reserva de ley.

Al aprobar una ley, los parlamentarios estatales y autonómicos están impregnando al uso administrativo de la fuerza física de legitimidad democrática, o están consintiendo que la administración pública limite los derechos y libertades de los ciudadanos que los han elegido como sus representantes parlamentarios, por tanto parece evidente que nos encontramos ante una situación (la del ejercicio de la actividad económica municipal si esta supusiera el ejercicio de una potestad como sostiene Montoya) con una habilitación legal que establezca una potestad que implique el ejercicio de autoridad o dirección ,que se entienden en una actividad reservada en monopolio a la administración, o como mucho en el ejercicio de actividades para la prestación de servicios públicos, pero entendemos que en ningún caso para el mero ejercicio de actividades económicas en pie de igualdad u otras muchas actividades que a nadie se le plantea, que aunque sean ejercidas en régimen de iniciativa pública en los términos del art. 128 de la Constitución, puedan estar sometidas a reserva de funcionario por implicar potestades.

Por otra parte, debe recordarse que esta potestad de iniciativa económica no aparece enumerada ni de refilón en el artículo cuarto de la LRBRL, donde se citan las potestades que ostentan las corporaciones locales, puesto que en este aspecto, en el de mero ejercicio de la actividad económica, no puede vincularse a la potestad de autoorganización, dado que la iniciativa no supone una organización de medios humanos materiales y financieros para el cumplimiento de un fin de servicio público, por lo menos para el ejercicio de actividades de "mercado".

Por tanto, la vinculación del artículo 86 LRBRL, en cuanto a la capacidad de ejercicio de iniciativa económica a una potestad; lo cual si pudiera plantearse en el caso de creación de empresas gestoras de servicios públicos, pero no en el caso de ejercicio de actividad económica libre, que además conforme a la redacción de la LRBRL, estaría vinculado a la ya comentada condición de funcionario por la expresa remisión al artículo noveno del EBEP, impide considerar en nuestra opinión a esa capacidad de ejercicio como una potestad, por la definición propia de potestad de ejercicio exorbitante, en tanto en cuanto, al estar en estos aspectos equiparada la iniciativa pública a la privada, y ser una mera facultad, no puede considerarse como potestad por ser esta, igualmente que concurre con el resto de las potestades con carácter general, de ejercicio inexcusable, y no transaccionales, como por ejemplo, implica el hecho de que la potestad auto organización queda al margen de la negociación colectiva, en el ámbito del empleo público, tal y como se determina en el artículo 37 del anteriormente citado EBEP32.

Cabe por tanto partiendo de esa diferente concreción de la iniciativa económica ., esto es por un lado la iniciativa económica de carácter empresarial "libre", que entendemos no puede configurarse por las razones argüidas como potestad, por otro lado el ejercicio de actividades en régimen de monopolio al amparo del art 86.2 LRBRL y la iniciativa económica para la prestación de servicios públicos.

31 Luis Cosculluela Montaner, op. cit., "Manual de derecho..."

32 Así al respecto puede estudiarse el trabajo de Ramón Parada Vázquez, “Derecho del empleo Público. Ley 7/2007, de 12 de abril, del Estatuto Básico del Empleado Público”, Marcial Pons 2007, Humberto Gosálbez Pequeño, Lorenzo Mellado Ruiz y María Luisa Roca FernándezCastanys, Manual básico del derecho del empleo público, Tecnos, 2013; AA.VV. Comentarios a la Ley del Estatuto Básico del Empleado Público, Editorial Lex Nova, Valladolid, 2007; Estatuto Básico del Empleado Público, Ed. La Ley-El Consultor, 2007; El Estatuto Básico del empleado público y su incidencia en el ámbito local, CEMCI, Granada, 2007; Comentarios a la Ley 7/2007, del Estatuto Básico del Empleado Público, Editorial Aranzadi, Pamplona, 2008; El Estatuto Básico del Empleado Público. Comentario Sistemático a la Ley 7/2007, de 12 de abril, de 2007, Comares, Granada, 2008; “El Estatuto Básico del Empleado Público. Propuestas de desarrollo legislativo por parte de las Comunidades Autónomas", El boletín CEMICAL, 2008; Manual de Empleo Público, IUSTEL, Madrid, 2009; Jiménez Asensio, R.; Castillo Blanco, F. Informe sobre el empleo público local. Balance y propuestas para su racionalización en el marco de la reforma del empleo público, Fundación Democracia y Gobierno Local, 2009. 
En estos dos últimos casos puede plantearse el ejercicio de funciones o poderes públicos por parte de las EELL y por tanto la existencia de, si no potestades,si algunas manifestaciones de supremacía pública.

\section{LA RESERVA DE ACTIVIDADES AL MONOPOLIO LOCAL}

\section{V.1 Consideraciones generales}

Si en el primer inciso del art. 128.2 de la Constitución, se alude a la iniciativa pública en la actividad económica, tal y como hemos analizado, en el segundo se regula la posibilidad de que por ley se reserven al sector público recursos o servicios esenciales.

Así en este supuesto de habilitación la actividad pública económica parece evidente que no concurrirá o coexistirá con la privada, como en el del mero ejercicio de la actividad previsto en el primer inciso, sino que, por el contrario, la iniciativa particular resultará excluida y, por tanto, también la libre competencia, prevaleciendo el interés general genérico, eso si consagrado mediante una expresa habilitación legal, que Ariño ${ }^{33}$ eleva a ley orgánica, sobre la libre competencia y la libertad de empresa, que el TFUE y el art 38 CE, determinan.

En este punto, se han proporcionado por la doctrina distintas interpretaciones sobre el alcance de este supuesto ${ }^{34}$, y así el ya señalado Sebastián Martín Retortillo35, sostiene que el inciso segundo del art. 128.2 de la Constitución sólo permite la reserva a la Administración de servicios «esenciales» en el sentido de los arts. 28.2 y 37.2 de la Constitución, que indican que las leyes que regulen los derechos de huelga y de planteamiento de conflictos colectivos incluirán las garantías precisas para asegurar el mantenimiento de los servicios esenciales de la comunidad.

Por su parte Fernández Farreres y Martín Rebollo ${ }^{36}$ mantienen la tesis sobre que la reserva de servicios al sector público únicamente cabe en aquellos que conlleven la gestión monopolística y directa por parte de la Administración, y por consiguiente los servicios públicos,cuya gestión pueda ser encomendada a terceros, quedarían excluidos del precepto.

Una tercera postura es la mantenida por De Juan Asenjo, Sosa Wagner y Entrena Cuesta ${ }^{37}$ que entienden encuadrada en el inciso segundo del art. 128.2 de la Constitución cualquier reserva de servicios a favor de la Administración, independientemente de que su posterior gestión sea directa o indirecta.

Por su parte Souvirón Morenilla ${ }^{38}$ apunta que en tal inciso segundo del art. 128.2 de la Constitución encuentra acomodo la atribución reservada a la Administración de servicios, sin perjuicio de que la gestión de cada actividad admita distintas posibilidades.

En apoyo de esta tesis, se encuentra la propia legislación positiva en desarrollo de este artículo. Así, la legislación sobre telecomunicaciones que publifica estos servicios, no sólo no prohíbe su gestión mediante concesionario interpuesto, sino que la regula como consecuencia propia de la citada reserva al sector público y, además, el propio Tribunal Constitucional tiene declarado que la reserva pública de servicios contenida en el art. 128.2 de la Constitución no impide la concesión de su gestión a particulares en los términos que establezca el legislador.

\section{V.2 La reserva de ley, naturaleza y tipos admisibles}

Podemos precisar y por tanto reseñar con Garcia Aparicio39, que el primer requisito, por tanto, para la existencia de una reserva de servicios a la Administración, radica en la necesidad de que la misma se produzca mediante ley en el sentido formal del término. De esta manera, los entes que carezcan de potestad legislativa, cual es el caso de las entidades locales, necesitarán de una ley previa que atribuya la reserva a su favor.

33 Gaspar Ariño Ortiz, Principios constitucionales de la libertad de empresa: libertad de comercio e intervencionismo administrativo, Marcial Pons, 1995, pág. 9.

34 Un estudio lo tenemos en Jose María Gimeno Feliú, "Sistema económico y Derecho a la libertad de empresa versus reservas al sector público de actividades económicas”, Revista de Administración Pública n 135, septiembre-diciembre de 1994 págs. 149 y ss.

35 Sebastián Martín Retortillo, Derecho Administrativo Económico l, la ley 1988, páginas 309 a 320 y 225 a 228.

36 Luis Martin Rebollo "Sociedad, economía y Estado: (a propósito del viejo regeneracionismo y el nuevo servicio público)" dentro de la obra colectiva Estudios de derecho público económico: libro homenaje al prof. Dr. D. Sebastián Martín-Retortillo, coord. por Luis Cosculluela Montaner, 2003, págs. 611-648 y Germán Fernández Farreres, Cuadernos aragoneses de economía, n 3, 1978-1979, págs. 217-226.

37 Rafael Entrena Cuesta, Alcance del principio de subsidiariedad en la legislación española, dentro de la obra colectiva Derecho administrativa: obra colectiva en homenaje al profesor Miguel S. Marienhoff, coord. por Juan Carlos Cassagne, 1998 , págs. $223-240$.

38 Jose Maria Souvirón Morenilla, La actividad de la administración y el servicio público, Comares, 1998.

39 José García Aparicio, “La iniciativa pública municipal en la actividad económica. Los Servicios Públicos de contenido económico”, El Consultor de los Ayuntamientos y de los Juzgados, n 18, Sección Colaboraciones, Quincena del 30 Sep. al 14 Oct. 1999, Ref. 2839/1999, pág. 2839, tomo 2, Editorial El Consultor de los Ayuntamientos y de los Juzgados. 
¿Ahora bien esa ley de que tipo será?, puesto que hay quien entiende, como el ya citado Ariño, que está reservada a la ley orgánica, cuestión que se cumplimentaría con una mera previsión en un Estatuto de Autonomía, que recuérdese tienen ese carácter, aunque retomando la teoría descrita por el profesor Gómez Ferrer ${ }^{40}$ sobre la función constitucional de las leyes cabría plantearse si es esta ,en relación con la Carta Magna, la función de los Estatutos.

Así en concreto, en Andalucía en virtud del art 32 de Ley 5/2010, de 11 de junio, de Autonomía Local de Andalucía, se reservan a favor de los municipios, los servicios públicos básicos, que se recogen en los artículos 92.2 d) del estatuto de autonomía, , aprobado por Ley Orgánica 2/2007, de 19 de marzo, de reforma del Estatuto de Autonomía para Andalucía(abastecimiento de agua y tratamiento de aguas residuales; alumbrado público; recogida y tratamiento de residuos; limpieza viaria; prevención y extinción de incendios y transporte público de viajeros), que en citado texto estatutario aparecen como meras competencias propias en cuanto a materias, pero que implican que la reserva habilite para la prestación efectiva en régimen de monopolio de los indicados servicios públicos, que aumentan y actualizan la lista del art 86 LRBRL.

En ese sentido debemos de plantearnos esos servicios en relación con los previstos con la legislación básica de régimen local, que conforme a las STC 103/2013, de 25 de abril fj 5 d), 143/2013, de 11 de julio fj 7 y 161/2013, de 26 de septiembre implican la necesidad de respeto por parte de la legislación autonómica de lo previsto en la LRBRL, aunque sea de CCAA con competencias "exclusivas " en régimen local, sin perjuicio de su desarrollo por estas, puesto que la reserva de ley no es estatal.

E igualmente en esta línea de confusión que implica la coexistencia de normas del año 1955 con reformas estatutarias, y reformas locales más recientes, debemos destacar, por tanto la vigencia del artículo 45, del reglamento de servicios de las corporaciones locales, de 17 de junio de 1955,con la nueva confusión terminológica entre la originaria municipalización , lo que en términos históricos ${ }^{41}$ suponía reserva, con el procedimiento del mero ejercicio de la actividad económica libre, ya estudiada, con la confusión normativa que ello genera, y así el citado art 45 RSCL establece:

1. La municipalización y la provincialización constituyen formas de desarrollo de la actividad de las Corporaciones Locales para la prestación de los servicios económicos de su competencia, asumiendo en todo o en parte el riesgo de la Empresa mediante el poder de regularla y fiscalizar su régimen.

2. Las municipalizaciones y las provincializaciones tenderán a conseguir que la prestación de los servicios reporte a los usuarios condiciones más ventajosas que las que pudiera ofrecerles la iniciativa particular y la gestión indirecta.

Igualmente en el Texto Refundido de las disposiciones legales vigentes en materia de régimen local, los artículos 96 a 98 recogen el procedimiento de "municipalización" e igualmente existen diversas normas autonómicas reguladoras de la materia y así por ejemplo la ley de autonomía local de Andalucía 5/2010 de 11 de junio, que en su artículo 32, indica:

Servicios públicos reservados

1. Se declara la reserva a favor de los municipios de los servicios públicos básicos enumerados en el artículo 92.2.d) del Estatuto de Autonomía para Andalucía. Mediante ley se podrá efectuar la reserva para otras actividades y servicios.

2. La reserva habilita para la prestación efectiva en régimen de monopolio de los servicios públicos referidos en el apartado anterior.

3. La prestación en régimen de monopolio de un servicio público será acordada por el pleno del ayuntamiento correspondiente, adoptado con el voto favorable de la mayoría absoluta del número legal de miembros de la corporación, previa la tramitación de un expediente acreditativo de la conveniencia y oportunidad de la medida, que incluirá, en todo caso:

40 Rafael Gómez -Ferrer Morant “La posición de la Ley General Presupuestaria en el ordenamiento jurídico”, dentro del libro colectivo, "El marco jurídico-financiero del sector público : perspectivas de reforma", 1986 , págs. 27-51.

41 Esta concreción histórica la tenemos en Nuria Magaldi Endeña, Los orígenes de la Municipalización de Municipios en España. El Tránsito del Estado Liberal al Estado Social a la luz de la liberalización de servicios públicos, INAP, 2012. 
a) Una memoria justificativa, que recogerá, entre otros extremos, la estructura del mercado sobre el que actúa la reserva, los posibles intereses empresariales afectados y las posibles compensaciones derivadas de la reserva; el concreto interés general que motiva la reserva y el cumplimiento de los criterios del Derecho europeo y nacional sobre la competencia relativos a la creación de los derechos especiales o exclusivos.

b) Un trámite de información pública y de audiencia a todos los sujetos directamente afectados por el proyecto de reserva.

c) Un informe provincial sobre cada concreto proyecto de reserva. El informe será obstativo cuando la reserva proyectada afecte de forma relevante al interés económico supramunicipal.

4. La recepción y uso de los servicios públicos reservados a las entidades locales podrá ser declarada obligatoria para los ciudadanos mediante ordenanza, cuando lo requiera la seguridad, salubridad o circunstancias de interés general.

Igualmente la ley de administración local de Aragón 7/1999, de 4 de abril, artículos 220 a 223, el Decreto legislativo 2/2003 de 28 de abril, por el que se aprueba el texto refundido de la ley municipal y de régimen local de Cataluña (artículos 243 a 247), el reglamento de obras, actividades y servicios de dicha Comunidad Autónoma, que lo regula los artículos 142 y siguientes, el 183 y siguientes, la ley Gallega de Administración Local 5/1997, de 22 de julio, que lo prevé en el artículo 309, la ley de las islas Baleares 20/2006, de 15 de diciembre, municipal y de régimen local que lo acoge en artículo 151, la ley de la Rioja 1/2003 de 3 de marzo, de administración local en su artículo 204, la ley de la Comunidad Autónoma de Madrid, 2/2003 de 11 de marzo, de administración local de dicha comunidad ,que lo establece en los artículos 98 a 103, la ley de administración local Navarra 6/1990 de 2 de julio, regulándolo en el artículo 216 y la ley de la Comunidad Valenciana de régimen local 8/2010 de 23 de junio, en los artículos 196 y siguientes.

Por tanto, la habilitación para la reserva de actividades es suficiente y consecuentemente, valga la redundancia, habilitante mediante ley, que no requiere la naturaleza estatal, en nuestra opinión, aunque si una supeditación a un criterio básico recogido por el artículo 86 LRBRL, para mantener el principio de unidad de mercado y la libre circulación de servicios, por una lógica vinculación al derecho comunitario, no pudiéndose reservar a unas Comunidades Autónomas si, y a otras no, determinados aspectos o actividades de naturaleza económica, puesto que esto generaría una distorsión en el mercado incompatible con dichas determinaciones de mercado único a nivel europeo y de unidad de mercado a nivel nacional ${ }^{42}$.

En cualquier caso, esa habilitación legal no requiere, puesto que no está expresamente prevista en la Constitución, tal y como determinó en el sentido de la interpretación de la reserva de ley orgánica, el alto interprete de la Carta Magna, de una ley de dicho sentido, sino, con una ley ordinaria es suficiente, y por tanto independientemente de la consideración anteriormente apuntada por el profesor Ariño, bastaría con una ley Autonómica incluso, eso si supeditada en base a la doctrina Constitucional, y por todas la Sentencia 103/2013, a la legislación básica estatal en esta materia.

\section{V.3 Carácter esencial de los servicios a reservar}

Como segundo requisito indispensable para que se produzca una reserva pública de servicios, se encuentra la de que éstos sean «esenciales», a modo de requisito objetivo previo a la declaración legal de reserva.

El concepto “esencial” no viene predeterminado o fijado por ninguna norma, lo más cercano es el concepto de servicio "obligatorio" recogido en el art 26 LRBRL, por lo que deberemos acotar este concepto jurídico indeterminado ( «servicio esencial»), que no cabe identificar sin más con el de «servicio público», ya que el segundo de los conceptos parece estar en relación de género a especie con respecto al primero.

Debemos en ese sentido recoger, tal y como destaca Souvirón Morenilla ${ }^{43}$, que puede distinguirse un significado "material” de la esencialidad de los servicios y un significado "lógico-formal”.

En su sentido material, los servicios esenciales objeto de posible reserva a tenor del art. 128.2, segundo inciso, de la Constitución se identificarían con los aludidos por el art. 28.2 del mismo texto, es decir, aquellos servicios

42 No obstante solicitado concepto y vinculación de la ley de mercado, existen muy distintas apreciaciones sobre la habilitación de dicha norma, en ese sentido podemos distinguir a Santiago Muñoz Machado "Sobre el restablecimiento legal de la unidad de mercado" Revista española de derecho administrativo, №163, 2014 , págs. 11-22 y Germán José Fernández Farreres “Unidad de mercado y libertades de empresa y de circulación en la Ley 20/2013, de 9 de diciembre”,Revista española de derecho administrativo, n 163, 2014, págs. 109-144.

43 Jose Maria Souvirón Morenilla, op. cit., La actividad de la administración y el servicio público, pág. 43. 
esenciales de la comunidad que deben ser garantizados aun frente al ejercicio del derecho de huelga. A este respecto, no debe olvidarse que los servicios esenciales a garantizar en caso de huelga, no sólo pueden tener el carácter de «servicio público» en sentido estricto, sino que perfectamente cabe configurar como tales "servicios privados», cuando resulten de indudable proyección sobre la colectividad, tal y como reconoció el Tribunal Constitucional en la STC26/1981, de 17 de julio, de las que deriven prestaciones vitales o necesarias para la vida de dicha comunidad, tal y como recuerda Fernández- Espinar ${ }^{44}$.

En cualquier caso la apreciación de esa "esencialidad" o no, le corresponderá al legislador competente y su control al Tribunal Constitucional.

\section{V.4 Necesidad de procedimiento previo}

Por otra parte, partiendo de estos dos presupuestos previos, esto es habilitación legal, y concepto de servicio esencial, lo cierto es que además de esos dos presupuestos habilitantes, se requiere un procedimiento singular que conforme al artículo 86.2 LRBRL, requerirá del expediente correspondiente y conforme al artículo 97 TRRL, de su tramitación y aprobación por el Pleno de la Corporación Local y posteriormente por el Consejo de Gobierno de la Comunidad Autónoma, previo informe del órgano competente de esta, si lo tuviere y si no, de la Comisión Nacional de los Mercados y la competencia, con respecto a su incidencia sobre la competencia.

Las circunstancias derivadas del derecho comunitario y la regulación de los servicios económicos de interés general con el concepto de servicios de interés general debe de llevar, conforme al concepto de servicios de interés general en la iniciativa económica local, a una diferenciación del procedimiento, tal y como apunta la reiteradamente citada Montoya ${ }^{45}$, puesto que aunque no compartimos su concepción como potestad en relación con la iniciativa económica ,si coincidimos en la necesidad de diferenciar el procedimiento correspondiente a los servicios públicos, o la implantación de servicios públicos, que tengan el concepto de interés general en la concepción de destinos a personas, de la pura iniciativa económica para aspectos que pueden ser perfectamente particulares, o que no tengan esa función de servicio público.

Así la citada autora plantea el mantenimiento o reproducción análoga del procedimiento previsto en el artículo 97 del TRRL, para los servicios públicos, mientras que por su parte requiere la necesidad de un procedimiento más simplificado para el ejercicio de la mera actividad económica, equiparándolo por tanto a los procedimientos y capacidades aplicables a un particular para el ejercicio de actividad económica.

Esta circunstancia de diferenciación del procedimiento es esencial, pero no solo para el ejercicio de los servicios públicos vinculados a una potestad y determinados por ley por el concepto de publificación a ellos mismos inherentes, sino también, para diferenciar la mera iniciativa económica, que en sí misma y con la supeditación lógica al cumplimiento del interés general determinada en este caso por la existencia de un cumplimiento de la estabilidad presupuestaria de los términos del artículo cuarto LOEPSF, y a la aprobación por el Pleno Corporativo como máximo representante de la voluntad popular del municipio, en la cual se concrete la supeditación o no al interés general conforme a las reglas democráticas, y por otra parte también un procedimiento específico y también diferenciado de los dos anteriores que contemple el ejercicio en monopolio de actividades económicas reservadas, que puede ser una variante de la iniciativa económica pero con mayores rigideces, y en este caso, en base a las determinaciones básicas legales supeditado a la aprobación del órgano autonómico correspondiente.

\section{LA INICIATIVA ECONÓMICA Y LA PRESTACIÓN DE SERVICIOS PÚBLICOS}

Así determinada la diferenciación entre iniciativa económica para la prestación de servicios públicos, especialmente los de carácter monopolístico e iniciativa económica, para la realización de actividades meramente económicas en plena igualdad sometidas al mercado, debemos destacar la necesidad, tal y como afirma Montoya Martín ${ }^{46}$; de diferenciar la actividad del servicio público, del ejercicio de lo que dicha autora denomina potestad de iniciativa pública económica, circunstancia que implica lógicamente a su vez, actualizar conceptos y en ese sentido, añadimos nosotros precisarlos y profundizar en ellos previamente a la adopción u análisis de cualquier elemento legislativo. Aunque está plenamente vigente el precepto que estudiamos no es tarde, en el aspecto ante el que nos encontramos, puesto que si la LRBRL, no fue necesaria de complemento o precisión en este ámbito

44 Luis Carlos Fernández-Espinar López, La nueva reforma local en relación a los servicios públicos y el régimen de intervención en las actividades de los ciudadanos (capítulo 4), págs. 167 a 242 de la obra colectiva La reforma del régimen local. Comentario a la ley 27/2013, de 27 de diciembre, de racionalización y sostenibilidad de la administración local, Tirant lo Blanch , 2014 dirigida por Tomás Quintana López , y en concreto, pág. 224 .

45 Encarnación Montoya Martín, op. cit., Las Fórmulas de Gestión de los Servicios Públicos Locales, pág. 250.

46 Encarnación Montoya Martín, Nuevas perspectivas sobre la gestión de los servicios locales: incidencia de la crisis económica y necesidad de racionalización del sector público instrumental, págs. 163 a 192, de la obra colectiva Anuario del derecho municipal, Marcial Pons. Universidad Autónoma de Madrid 2011. Año 2012, y en concreto págs. 171-172. 
durante todos sus largos años de vigencia en la redacción original, tampoco ocurre nada porque ahora no se haya incorporado en la propia ley una precisión técnica en esa línea.

Eso sí es una oportunidad perdida, que puede fácilmente salvarse mediante un correcto desarrollo reglamentario, máxime cuando el reglamento de servicios de las corporaciones locales, norma vigente de importancia, no solo doctrinal ${ }^{47}$, sino de importante aplicación en la prestación concreta de los servicios locales, requiere de una importante actualización, y proceder a superar cualquier referencia el concepto de municipalización y provincialización de servicios, actualizando a un marco europeo esta fórmula de iniciativa económica y prestación de servicios públicos locales.

En esa línea, y manteniendo la necesidad de precisión conceptual que debería de acoger no solo la ley, sino la reglamentación de desarrollo, cabe distinguir lógicamente entre el concepto de competencia, el concepto de materia y el concepto de servicio, pero además complementarlo con el concepto de atribución, en cuanto, a los términos recogidos por Alessi48.

Por tanto, deben recogerse dentro de cada entidad dotada de competencias, las funciones o atribuciones de los órganos concretos, máxime en régimen local por la diferenciación existente entre la dualidad, Alcaldía-Pleno, y en los municipios de gran población, junta de Gobierno.

En este ánimo de precisión debemos recordar que pese a la confusión existente entre servicios y actividades económicas, no todos los servicios tienen un contenido económico, independientemente de que tengan todos una lógica presupuestación, dado que por contenido económico entendemos la participación de ingresos de terceros directamente vinculados a la actividad concreta, esto es lo que García de Enterría denominaba actividad industrial o mercantil ${ }^{49}$.

Así en ese sentido, igualmente no todos los servicios públicos implican prestaciones vinculadas al ejercicio de autoridad, sino que, al menos algunos de ellos como los servicios sociales, implican una mera actividad prestacional, que puede ser mayor o menor en el caudal y actividad general del municipio, tal y como recuerda Morillo Velarde ${ }^{50}$, pero que obviamente tienen en muchas ocasiones como hemos apuntado antes, un profundo carácter ideológico, y así, desde el origen de la propia actividad económica, tal y como ha recordado Meilan Gilis1, vinculando al de la incipiente burguesía por estar esta condicionada por la gestión privada mediante concesión a través de la obra pública, o directamente sea connatural a los servicios públicos en el momento de su configuración jurídica, como determinación teórica que proporciona un título atribuido a la administración pública, consistiendo esto a juicio de Meilan, la novedad.

En ese aspecto, debe señalarse que la competencia establece una capacidad para el establecimiento del servicio público, pero no una relación directa de equivalencia, tal y como analiza Ortega Bernardo ${ }^{52}$.

Por otro lado, la existencia de servicios públicos vinculados al cumplimiento de las competencias públicas, que a su vez pueden ser obligatorios conforme al artículo 26 de la LRBRL, y que lógicamente en buena medida se regirán por un régimen de derecho público vinculada a la publificación, o publicatio de dicho servicio, independientemente de la fórmula concreta que se adopte, tal y como reseñó Malaret ${ }^{53}$.

Finalmente, debe recogerse igualmente la existencia de actividades que conforme a la LRBRL, tienen un carácter monopolístico, en ese sentido, tal y como se definió por la ley 57/2003, de 16 de diciembre de medidas para la modernización del Gobierno Local, con respecto a la LRBRL, lo cierto es que, la precisión del concepto del servicio público local, tal y como afirma del Guayo Castiella ${ }^{54}$, que dicha reforma del artículo 85 de la LRBRL, tuvo por consecuencia, que son los servicios públicos locales y no otras actividades o servicios locales de naturaleza económica, del análisis de la iniciativa pública económica local , los que pueden gestionarse mediante alguna de las formas contempladas en el artículo 85.2 de la citada LRBRL, y concretamente, que son los servicios públicos locales(excepto los que impliquen autoridad)los que pueden gestionarse indirectamente.

47 Así al respecto sobre el concepto de servicio público local, y su múltiple incidencia véase el volumen "Los Servicios Públicos Locales” Actas del XXVII Congreso Iberoamericano de Municipios, Federación Española de Municipios y Provincias de 2009.

48 G. Alessi, Princippi di diritto amministrativo, Milán, 1974.

49 Eduardo García de Enterría, “La actividad industrial y mercantil de los municipios”, Revista de administración pública, n 17, 1955 , págs. 87-138.

50 Jose Ignacio Morillo Velarde, “La gestión de servicios de las entidades locales”, capítulo XV, págs. 1267 a 1302 , de la obra colectiva dirigida por Tomas Cobo Olvera, Tratado de Derecho Local, Aranzadi Thomson- Reuters, 2010, y en concreto pág. 1273

51 Jose Luis Meilan Gil, “Progreso tecnológico y Servicios Públicos” Thomson Civitas, 2006 pág. 13.

52 Julia Ortega Bernardo, "Competencia, servicio público y entidad económica de los municipios (presupuestos actuales para su delimitación y su ejercicio)”, Revista de administración pública n¹69, Centro de Estudios Políticos y Constitucionales, Madrid 2006.

53 Elisenda Malaret García, "Servicios públicos actividad económica y competencia ¿presenta especificidades la esfera local?” Revista de Estudios de la Administración Local y Autonómica, n² 291, INAP, 2003, págs. 567-608.

54 Iñigo del Guayo Castiella, op. cit., pág. 493. 
En ese sentido, existe una contraposición de la citada redacción de la LRBRL, y el artículo 95.1 del TRRL que admitía que fueran gestionadas indirectamente no solo los servicios públicos locales, si no también otros servicios locales que se establecieran en virtud de la iniciativa pública prevista en el artículo 86, contribuyéndose a aclarar tras la reforma la determinación del artículo 86.2, de la versión original de la ley básica.

Esa interpretación que mantiene del Guayo ${ }^{55}$, es probablemente congruente en relación con la determinación del artículo 97 del TRRL, sobre el procedimiento para el ejercicio de las actividades, que solo son referibles a los servicios públicos, de aquellos que se aplican al ejercicio de la libre iniciativa económico local y no a otros comunes a ambos; en ese sentido, debe reseñarse que la LRSAL, ha derogado ese aspecto del anterior artículo 86.2.

No se aclara tras la LARSAL la confusión, al mantener el apartado final, en cuanto al contenido del expediente que se recogerá, "la forma concreta de gestión del servicio", circunstancia esta claramente vinculada al ejercicio de servicios públicos.

En dicha línea, y tal y como se encarga de precisar Del Guayo Castiella ${ }^{56}$, lo cierto, es que la concepción del servicio público tan discutida puede vincularse, como hace el citado autor, tan solo, (y en su opinión no todos, cuestión de la que discrepamos), a los servicios previstos en el artículo 26 LRBRL y a los establecidos en virtud de la iniciativa económica del artículo 86 de dicha legislación básica.

Esto supondría, que el ejercicio de competencias que no tuvieran un contenido económico y que no estuvieran previstas en el conjunto de los servicios del artículo 26, no tendrían la condición de servicio, circunstancia esta que como señalamos es más que discutible, puesto que igual que el concepto de servicio esta vinculado, conforme señala el Tribunal Supremo, a la competencia esto es, al desempeño de ésta, es evidente que no es equivalente en su amplitud ,tampoco puede ser genérica, en tanto en cuanto, el servicio público requiere de una publicatio para la satisfacción de las necesidades, sometida a un régimen jurídico de carácter administrativo ${ }^{57}$.

Lo cierto es, que la LRSAL, al disminuir el número de competencias, al precisarlas y vincularlas necesariamente, en cuanto al desempeño para las complementarias o impropias, al principio de estabilidad presupuestaria, ha disminuido enormemente el elenco y abanico de servicios que pueden considerarse de carácter público.

En cualquier caso, la concepción de servicio reservado como servicio público también tiene un carácter discutible desde un punto de vista conceptual ,aunque no práctico, puesto que la reserva que realiza el artículo 86.2, al igual que la que hacía el artículo 86.3, en la redacción originaria de la LRBRL, supone servicios de un carácter esencial para la comunidad como es el transporte público, que además está publificado por normas sectoriales, como la ley de ordenación de los transportes terrestres ${ }^{58}$, el suministro de agua a las poblaciones ${ }^{59}$ y la recogida y eliminación de los residuos sólidos ${ }^{60}$, vinculados todos a servicios absolutamente indispensables que por regímenes jurídicos específicos, el texto refundido de la ley de aguas, y en el caso de la Comunidad de Madrid, por ejemplo, la ley 17/1984, en Andalucía por la ley de aguas de la Comunidad Autónoma etc., y en el caso de los residuos por la ley de residuos y suelos contaminados, quedan no solo reservados sino publificados necesariamente, desde un punto de vista no solo local sino sectorial, en manos del poder público en este caso municipal.

En cualquier caso, lo cierto, es que la panoplia de los servicios públicos, tal y como hemos advertido levemente, en el ámbito municipal y local en general, han quedado disminuidos, en tanto en cuanto, el ejercicio de las competencias propias queda supeditado lógicamente al listado de materias previstas en el artículo 25, materias que nuevamente no se precisan en cuanto su aspecto contenido y extensión para fijar las correspondientes competencias.

Recuérdese que competencia es la capacidad para conocer por parte de un ente público, mientras que la atribución es la capacidad del órgano concreto dentro del Ente público competente y finalmente debe recordarse que la materia con carácter general no implica el ejercicio de competencia, puesto que se remite a la legislación estatal o /y autonómica correspondiente en cada materia, no recogiéndose por ejemplo, en materia de tráfico y movilidad, las funciones concretas en el casco urbano que corresponden a un municipio, si no simplemente, la materia lo cual se fijará en las competencias en este caso por el texto refundido de la ley sobre tráfico vehículo a motor y seguridad vial estatal. $\mathrm{O}$ en el ámbito urbanístico de planeamiento, gestión y disciplina urbanística y en

55 Iñigo del Guayo Castiella, op. cit., pág. 494.

56 Iñigo Del Guayo Castiella, op. cit., pág. 494

57 Y así lo indican Luis Carlos Fernández-Espinar López, op. cit., pág. 236 y Elisenda Malaret Garcia, op. cit., pág. 603.

58 Al respecto de dicha redacción legal originaria es esencial la STC118/1996.

59 Sobre esta materia puede consultarse nuestra aportación Fernando García Rubio, Regimen jurídico de la gestión del agua, El consultor de los Ayuntamientos y de los juzgados-La ley, 2010.

60 Al respecto vid. Jose Francisco Alenza García, “Aspectos jurídicos de la regulación de los residuos sólidos urbanos”, págs. 317 a 344 , de la obra colectiva dirigida por Diego José Vega Jurado, El medio ambiente urbano, CEMCI, 2003 y en concreto pág. 326. 
su caso rehabilitación que quedan remitidas al texto refundido de la ley estatal de suelo 2/2008 y a las diferente leyes autonómicas, por ejemplo la ley 9/2001, de 17 de junio de la Comunidad Autónoma de Madrid, y a la ley de ordenación urbanística de Andalucía, fijándose las competencias concretas en materia de Planeamiento, (esto es formulación y aprobación inicial y provisional), gestión (formulación y aprobación, en su caso, de los instrumentos de equidistribución de beneficios y cargas), y disciplina( licencias, restauración de la legalidad y régimen sancionador).

Aquí normalmente la LRSAL, tal y como ha afirmado la doctrina con carácter generalo1, ha perdido una oportunidad para precisar y diferenciar esos conceptos que además de ser importante para los teóricos, también tiene una vertiente práctica en cuanto a fijar capacidades que reforzarían la autonomía local, porque vendrían determinados por la legislación básica local, y no por la legislación concreta sectorial modificable mucho más fácilmente, y recuérdese incluso sin dictamen de la Comisión Nacional de Administración Local, esto es sin una mínima audiencia a las AAPP que deben aplicar esas normas.

Ahora bien, partiendo de ese aspecto y diferenciación competencial, lo cierto es que entendemos que los servicios públicos serán aquellos que se ejerzan en virtud de competencias propias de la entidad local, pero no solo los servicios obligatorios del artículo 26 , si no, cualesquiera otros vinculados a esas competencia propias o a aquellas competencias delegadas en virtud de lo dispuesto por el artículo 27 LRBRL, de forma específica por otra administración ,puesto que la gestión del servicio, esto es el ejercicio de la competencia y supuesta acción a los ciudadanos corresponderá a la entidad local.

En ese sentido, es perfectamente posible, puesto que simplemente se exigen en la LRSAL, y por consecuente en la LRBRL, la determinación de la forma de gestión del servicio público mediante una sociedad mercantil, sociedad que por su naturaleza tiene un carácter económico, e incluso tras la sibilina prohibición anteriormente comentada para las EPES del ejercicio de potestades mediante la citada fórmula organizativa de entidad pública empresarial ,las cuales tienen una repercusión en la libre prestación de servicios y en el tráfico mercantil.

Es más, es que hay servicios públicos que por su naturaleza pueden ser prestados alternativamente o complementariamente por la actividad privada, lo cual contradice mucho el concepto en sí mismo de servicio público, pero que es tradicionalmente admitido, especialmente en el ámbito local, por la amplia concepción que tiene la naturaleza del servicio público local al vincularse a la competencia.

Por tanto esta circunstancia de posibilidad de ejercicio de servicios públicos mediante sociedades mercantiles o EPES, no supone en si mismo una actividad económica, aunque si, una vinculación al procedimiento de ejercicio de actividad económica, conforme a las determinaciones de los artículos 86.2 LRBRL, en relación con el 97 del TRRL. Lo cual abunda en la necesidad de precisión de los conceptos a que hemos hecho referencia y las confusiones que ello podría generar, sino se procede a ello.

Otra cuestión posible es que los servicios públicos solo pudieran ejercitarse mediante formas de gestión directa, cuestión esta que más o menos es el objetivo final de la LRSAL, puesto que aunque establece periodos mayores de carencia en cuanto a la necesidad de liquidación de sociedades mercantiles que generen pérdidas, gestoras de servicios públicos(agua , transportes y residuos) no establece una excepción en la disolución para dichas empresas de aguas, transportes o residuos si no que simplemente especifica la necesidad de liquidación de la forma gestora mediante sociedad mercantil, pero lógicamente debiendo mantenerse el servicio, puesto que es obligatorio y monopolístico, en virtud de los artículos 86.2 y 26 de la LRBRL.

Debe precisarse en ese sentido que la distinción entre servicios públicos y servicios en régimen de libre competencia tiene además su especial importancia por la operatividad de la prohibición de ayudas comunitarias, puesto que nos encontramos en base a la propia doctrina comunitaria para diferenciar los servicios sociales, o de bienestar social, de los servicios económicos de interés general ${ }^{62}$. Señalándose igualmente que existe una falta de distinción en el Tratado entre el servicios económico y los servicios no económicos ${ }^{63}$.

En ese sentido, cuando nos encontramos con reglas de competencia y prohibición de ayudas europeas, tiene especial importancia la consideración de que afecta la competencia en este ámbito, incluyendo por tanto las sociedades mercantiles o actividades económicas que sean desarrolladas por las entidades locales en el ámbito de esa competencia.

61 Una visión general se puede contemplar en Lorenzo Mellado Ruiz, Génesis y realidad de la Ley 27/2013, de 27 de diciembre, de racionalización y sostenibilidad de la administración local: ¿una nueva reforma económica local?, CEMCI, 2014.

62 Al respecto de dicha concepción vid Luis Carlos Fernández-Espinar López, op cit, págs. 227-228.

63 Encarnación Montoya, op cit., “Las Fórmulas...”, pág. 220. Dictamen del Comité de las Regiones de 16 de enero de 1997 sobre el papel de las autoridades locales y regionales de los servicios públicos. 
Y así por ejemplo en un aspecto tan concreto como los transportes públicos, muchas veces necesitados de ayudas para el mantenimiento del concepto y función de servicio público y por el carácter deficitario de la necesidad de llegar a núcleos de poblaciones separados que no hacen rentable económicamente las correspondientes líneas, y así en ese sentido debemos destacar, el criterio del Tribunal de justicia de la Unión Europea en la Sentencia TJCE de 24 de julio de 2003/ALTMARK, trans(C-280/00) que establece que la citada política de subvenciones solo se comprende siempre que va tener una incidencia fuera del estado miembro, no restringir la competencia, esto es lo que se ha venido a considerar como la denominada doctrina Mínimis que recoge una excepción a la regla de la libre competencia, para la posibilitación de la prestación de servicios públicos de carácter esencial o necesarios para la comunidad, sobre todo en el ámbito intraestatal, que no incide en la competencia e igualdad entre empresas de estados miembros.

No obstante esta cuestión ha sido debidamente abordada por la Unión, tal y como recuerda Villalba Perez $z^{64}$ y así la guía de la Comisión Europea de 24 de abril de 2013 para la aplicación por los Estados miembros de las reglas y normas sobre ayudas estatales, contratación pública, y el mercado interior de los servicios de interés general y en particular de los servicios sociales de interés general.

Igualmente lo recoge el reglamento UE 360/2012 de la Comisión, de 25 de abril de 2012, relativo a la aplicación de los artículos 107 y 108 del TFUE a las ayudas de minimis concedidas a empresas que prestan servicios de interés económico general.

En esa línea, la decisión 2012/21/UE de la Comisión de 20 de diciembre de 2011, relativa a la aplicación de las disposiciones del artículo 106.2 del TFUE a las ayudas estatales en forma de compensación por servicio público, concedidas a algunas empresas encargadas de la gestión de servicios de interés económico general.

Por otro lado la Comunicación de la Comisión de 11 de enero de 2012, Marco de la Unión Europea sobre ayudas estatales en forma de compensación por servicio público y la Comunicación de la Comisión Europea de 20 de diciembre de 2011, relativa a la, aplicación de las normas de la UE en materia de ayudas estatales a las compensaciones concedidas por la prestación de servicios de interés económico general.

En cualquier caso, tal y como recuerda el considerando sexto de la directiva sobre contratos de concesión:

Cabe recordar que los Estados miembros son libres, dentro del respeto de los principios del TFUE sobre igualdad de trato, no discriminación, transparencia y libre circulación de personas contemplados en el Tratado, de decidir organizar la prestación de servicios, ya sea como servicios de interés económico general, como servicios no económicos de interés general, o como una combinación de ambos. Cabe recordar asimismo que la presente Directiva se entiende sin perjuicio de la libertad de las autoridades con el Derecho de la Unión, los servicios de interés económico general, su ámbito de aplicación y las características del servicio, incluidas las eventuales condiciones relativas a la calidad del servicio, con el fin de lograr sus objetivos de interés público. Tampoco menoscabará la competencia de las autoridades nacionales, regionales y locales para prestar, encargar y financiar los servicios de interés económico general, de acuerdo con el artículo 14 del TFUE y el Protocolo $n^{\circ}$ 26 sobre los servicios de interés general, anejo al TFUE y al Tratado de la Unión Europea (TUE). Asimismo, la presente Directiva no aborda la financiación de servicios de interés económico general ni los sistemas de ayuda concedidos por los Estados miembros, en particular en el ámbito social, de conformidad con las normas de la Unión en materia de competencia. Conviene aclarar que los servicios no económicos de interés general deben quedar excluidos del ámbito de aplicación de la presente Directiva

Por tanto los servicios públicos mantienen un importante aspecto extramercado que la propia Unión reconoce.

\section{LA INICIATIVA ECONÓMICA LOCAL. DETERMINACIONES PROCEDIMENTALES PARA SU EJERCICIO}

\section{VII.1 Cuestiones previas al inicio del procedimiento}

Así una primera cuestión antes de abordar el procedimiento para el ejercicio de la actividad económica local, tal y como recoge García Aparicio ${ }^{65}$, es la de determinar si la iniciativa pública en la actividad económica tiene un carácter incondicionado o, por el contrario, está sujeta a limitaciones, en particular las derivadas del interés general que la Administración está obligada a observar en todas sus actuaciones, conforme al art. 103.1 de la Constitución.

64 Francisca Villalba Pérez, “La concesión de servicios, nuevo objeto de regulación del Derecho Comunitario. Directiva 2014/23/UE de 26 de febrero de 2014 relativa a la adjudicación de contratos de concesión”, REALA, n² 2 (nueva época) julio-diciembre 2014.

65 José García Aparicio, “La iniciativa pública municipal en la actividad económica. Los Servicios Públicos de contenido económico, Secretario de Administración. Categoría Superior”, El Consultor de los Ayuntamientos y de los Juzgados, n 18, Sección Colaboraciones, Quincena del 30 Sep. al 14 Oct. 1999, Ref. 2839/1999, pág. 2839, tomo 2, Editorial El Consultor de los Ayuntamientos y de los Juzgados. 
Con carácter previo debe destacarse, junto a la regulación legal en la materia , la importante jurisprudencia existente al respecto y así la STS de la Sala Tercera, de lo Contencioso-administrativo, Sección $1^{\mathrm{a}}$, de 10 Oct. $1989^{66}$, que en su fundamento jurídico tercero indica:

\begin{abstract}
Las anteriores afirmaciones deben sin embargo matizarse enseguida en un doble aspecto. Por un lado, mientras los particulares pueden crear sus empresas con plena libertad de criterios, sin más condición que la de que sus fines sean lícitos (artículo 38 de la Constitución), todas las actuaciones de los Órganos de la Administración Pública deben responder al interés público que en cada caso y necesariamente siempre ha de concurrir (art. 103.1 de la Constitución), tanto si se trata de actos de autoridad, como de actuaciones empresariales, pues en cuanto a estas últimas el art. 31.2 de la propia Constitución también exige una equitativa asignación de los recursos públicos y que su programación y ejecución responda a criterios de eficiencia y de economía, lo cual no es compatible con actuaciones empresariales públicas carentes de justificación. Por otra parte, la coexistencia de empresas públicas con fines empresariales (artículo 128.2 de la Constitución) y de empresas privadas (artículo 38 de la misma) en el marco de una economía de mercado, y la pertenencia de España a la Comunidad Económica Europea, exigen que se garantice y salvaguarde la libre competencia, y para ello han de regir las mismas reglas para ambos sectores de producción público y privado. Por tanto, las empresas públicas que actúen en el mercado, se han de someter a las mismas cargas sociales, fiscales, financieras y de toda índole que afecten a las privadas y a sus mismos riesgos, sin poder gozar de privilegios de ningún tipo, pues ello podría impedir, restringir o falsear el juego de la libre competencia del mercado vulnerando el artículo 85 del Tratado de Roma, no pudiendo tampoco estas empresas de capital público prevalecerse de ninguna forma de posición dominante ni subordinar la celebración de contratos a la aceptación por los otros contratantes de prestaciones suplementarias que por su naturaleza o según los usos mercantiles, no guarden relación alguna con el objeto de dichos contratos (art. 86 del mismo Tratado); y no pueden por último estas empresas privadas de capital público recibir ayudas ni subvenciones de fondos públicos de ninguna clase, con las solas salvedades que enumeran los apartados 2 y 3 del artículo 92 del Tratado, y aun siempre sometiendo previamente las excepciones (con una antelación mínima de 3 meses antes de poder aplicarlas) a la consideración de la Comisión del Mercado Común (artículos 93.3 del Tratado y $1^{\circ} .1$ del Real Decreto 1755/1987 de 23 de diciembre). En resumen: la creación de empresas públicas para fines empresariales es legalmente posible, pero está sujeta a la doble condición de que la actividad empresarial que se vaya a desarrollar con la empresa pública sea una actividad de indudable interés público apreciable y apreciado en el momento de su creación, y que en el ejercicio de la actividad económica empresarial de que se trate la empresa pública se someta sin excepción ni privilegio alguno directo ni indirecto a las mismas reglas de libre competencia que rigen el mercado
\end{abstract}

Por tanto una primera cuestión es la indispensable necesidad de acreditar la conveniencia para el interés general de cada iniciativa económica, lo cual en buena lógica se plasmara en la moción o propuesta correspondiente que de inicio al expediente.

Así, con respecto al expediente de ejercicio de la actividad propiamente dicho, la diferenciación anteriormente apuntada, sobre iniciativa pública económica en régimen de libre concurrencia y de igualdad, con los particulares, e iniciativa pública económica, en materias vinculadas a la gestión de servicios públicos, reservados a la administración es clave, puesto que hay alguna doctrina ,como por ejemplo Montoya Martín ${ }^{67}$, que establece la necesidad de tramitar la aprobación de los estatutos de las entidades públicas empresariales y organismos autónomos, no solo en cuanto en unidad de acto para su constitución, tanto para la prestación de un servicio esencial en régimen de monopolio, si no también, en régimen de libre concurrencia, así como de actividades no reservadas a la administración local, por lo que siempre que a su juicio, se ha tramitado expediente relativo a la conveniencia y oportunidad de la medida, sin en unidad de acto se decide la modalidad organizativa, y se adopta sus estatutos, cabe plantearse por que no establecer una modalidad procedimental diferenciada, para uno u otros aspectos del ejercicio de la iniciativa económica, cuestión esta que compartimos.

No obstante, las entidades locales podrán ejercer la iniciativa pública para el desarrollo de actividades económicas, siempre que esté garantizado el cumplimiento del objetivo de estabilidad presupuestaria y de la sostenibilidad financiera del ejercicio de sus competencias, y solo en esos casos.

En el expediente acreditativo de la conveniencia y oportunidad de la medida habrá de justificarse que la iniciativa no genera riesgo para la sostenibilidad financiera del conjunto de la Hacienda municipal, debiendo contener un análisis del mercado, relativo a la oferta y a la demanda existente, a la rentabilidad y a los posibles efectos de la actividad local sobre la concurrencia empresarial. Corresponde al pleno de la respectiva Corporación local la aprobación del expediente, que determinará la forma concreta de gestión del servicio.

66 Es la celebérrima sentencia sobre la empresa Iniciatives S.A. del Ayuntamiento de Barcelona, ponente: Antonio Bruguera Manté, LA LEY 2902/1989.

67 Encarnación Montoya Martín, op. cit. “Las entidades públicas...”, pág. 99 
Se ha eliminado en el texto definitivo aprobado las redacciones precedentes que suponían implantar sólo para la Administración local el principio de subsidiariedad en la actividad económica pública. El apartado 3 del art. 86 versión precedente LRBRC sometía tanto el ejercicio de iniciativa pública económica en régimen de competencia como las actividades reservadas a la aprobación definitiva del órgano autonómico correspondiente, lo cual a juicio de la citada autora contravenía directamente el art. 128.2 CE que reconoce sin ambages la iniciativa pública económica, así como la autonomía local ${ }^{68}$, al someter su ejercicio a una especie de principio de subsidiariedad y requerir en todo caso acuerdo del Gobierno autonómico

No obstante la reforma de la LRSAL ha perdido en este aspecto una oportunidad de oro para establecer dos cauces procedimentales, pese a que en algunos aspectos como en las disposiciones transitorias sobre extinción de empresas si ha diferenciado en los plazos de adaptación para incurrir en disolución a las que gestionan servicios públicos esenciales en régimen de reserva y al resto de las empresas locales que deben disolverse por no cumplimentar las determinaciones de la LRSAL

Sobre estas circunstancias de la fase procedimental para el ejercicio de las actividades que son, realmente las verdaderas diferencias en cuanto a una iniciativa pública, especialmente la local en materia económica, con una iniciativa empresarial particular por la sujeción a norma de derecho administrativo de los "actos separables" del procedimiento de constitución, es por lo que tendremos que tener en cuenta estas circunstancias.

El procedimiento recogido en el artículo 97 del Texto Refundido del Régimen Local, en las diferentes legislaciones autonómicas anteriormente reguladas y en el Reglamento de Servicios de Corporaciones Locales, supone la existencia de algunas variaciones.

A la vista de esta confusión terminológica, anteriormente apuntada, con la necesidad de superación del actual concepto de municipalización ${ }^{69}$, no podemos compartir lo que se afirma por Montoya ${ }^{70}$, sobre suprimir cualquier referencia, al concepto de municipalización, y provincialización como expresivo vestigio de un estado liberal, en el que la iniciativa económica local, constituía algo excepcional. Puesto que, partiendo de que el estado actual como estado social, permite (la iniciativa económica pública en pie de igualdad), lo que procede es una reactualización del concepto, en tanto en cuanto, se permite, siempre que haya una ley habilitante, la expropiación por parte de los municipios y entidades provinciales, que recuérdese, están dotadas de potestad expropiatoria de forma expresa por la ley de 16 de diciembre de 1954, y a su vez, en el artículo cuarto de la LRBRL, para privar una empresa concreta a sus propietarios, mediante el correspondiente expediente con el justo precio, y por tanto, sometiéndolo a titularidad pública, con los requisitos legales evidentes, no solo de la expropiación, sino de la habilitación previa, y la subsiguiente prestación del servicio por parte municipal.

En ese sentido también puede hablarse de esta materia, de un modo impropio jurídicamente, de la figura de los rescates o recuperación de servicios concedidos en el marco de la crisis, lo que supone una "municipalización" de estos, tal y como por ejemplo ha concurrido en el caso de Jerez de la frontera con la recogida de residuos.

Ahora bien, evidentemente ya el concepto de monopolio municipal, como fue en sus comienzos el gas, o incluso en momentos concretos la venta de pan, como en 1905 en alguna localidad, no puede contemplarse en nuestro actual estado de derecho, salvo para aquellos supuestos del artículo 128.2 en su inciso segundo, que se recogen actualmente en el 86.2 de la LRBRL, tras la reforma de la ley de Racionalización, puesto que el principio de libertad de empresa y la libre circulación europea lo impedirían.

Pero eso no implica que se deba suprimir el concepto en su conjunto, sino simplemente readaptarlo y precisarlo a los tiempos actuales, puesto que igual que existe la posibilidad de nacionalización, y seguramente "Autonomización", puede seguir existiendo la Municipalización entendida como la hemos apuntado.

\section{VII.2 Procedimiento para el ejercicio de actividades monopolísticas}

Desde un punto de vista procedimental, debemos destacar que, puesto que las actividades económicas que se pretender realizar en régimen de monopolio, deberán de cumplimentar un nuevo cauce procesal, conforme a

68 Sobre esta materia entre otros, a título enunciativo puede consultarse Francisco Velasco Caballero "Los municipios y la autonomía municipal” dentro de: “Lecciones y materiales para el estudio del derecho administrativo”, obra colectiva / coord. por Tomás Cano Campos, vol. 2, 2009 (La organización de las administraciones públicas), págs. 133-169, lustel , Nemesio Rodríguez Moro, "En torno a la autonomía municipal” dentro de la obra colectiva Homenaje a Carlos Ruiz del Castillo, coord. por Manuel Aragón Reyes, 1985, págs. 487-510, José Luis Carro Fernández-Valmayor, "El debate sobre la autonomía municipal” igualmente dentro del trabajo colectivo "El derecho administrativo en el umbral del siglo XXI : homenaje al profesor Dr. D. Ramón Martín Mateo”, coord. por Francisco Sosa Wagner, 2000, págs. 545-580 Antonio Embid Irujo, “Autonomía municipal y Constitución: aproximación al concepto y significado de la declaración constitucional de autonomía municipal”, Revista española de derecho administrativo, $n^{\circ} 30,1981$, págs. 437-470.

69 Sobre el origen histórico de este puede verse Nuria Magaldi Mendaña, "La primera doctrina española sobre la municipalización de servicios públicos: en particular, la recepción de la doctrina extranjera por el profesor Gascón y Marín”, págs. 165 a 219 del n³9-40 de la Revista Aragonesa de Administración Pública, 2012.

70 Encarnación Montoya Martín, op. cit., Nuevas perspectivas sobre... pág. 173

REALA, n 3, enero-junio 2015, ISSN: 1989-8975 - DOI: http://dx.doi.org/10.24965/reala.v0i3.10238 
la nueva redacción otorgada al artículo 97.2 del Texto Refundido de las Disposiciones legales vigentes en materia de Régimen Local, aprobado por Real Decreto Legislativo 781/1986, de 18 de abril, establecido por la Disposición Adicional Primera, de la Ley de Racionalización y Sostenibilidad de la Administración Local, que establece un nuevo apartado 2 del indicado artículo 97 del TRRL, y en concreto con la siguiente dicción:

\section{Artículo 97}

2. Para la ejecución efectiva en régimen de monopolio de las actividades reservadas de acuerdo con lo dispuesto en el artículo 86.2 de la Ley 7/1985, de 2 de abril, Reguladora de las Bases de Régimen Local , se requerirá el cumplimiento de los trámites previstos en el número anterior referidos a la conveniencia del régimen de monopolio y se recabará informe de la autoridad de competencia correspondiente, si bien el acuerdo a que se refiere su apartado d) deberá ser optado por mayoría absoluta del número legal de miembros de la Corporación.

Recaído acuerdo de la Corporación, se elevará el expediente completo al órgano competente de la Comunidad Autónoma. El Consejo de Gobierno de ésta deberá resolver sobre su aprobación en el plazo de tres meses.

Si se solicitase dictamen del Consejo de Estado o del órgano consultivo superior del Consejo de Gobierno de la Comunidad Autónoma, donde existiese, no se computará el tiempo invertido en evacuar la consulta.

En ese sentido, junto al expediente acreditativo de una actividad económica, con la memoria correspondiente prevista en el artículo 97.1, tal y como en su momento indicara Martín Mateo ${ }^{71}$, nos encontramos con la necesidad expresa de que exista un informe de la autoridad de la competencia y además el acuerdo de aprobación de dicho ejercicio de la actividad económica por parte de la corporación local, que debe ser adoptado por mayoría absoluta de los miembros de la Corporación.

Ahora bien, ese acuerdo de la Corporación, no es el que habilita para el ejercicio directo de la actividad local, puesto que nos encontramos ante un régimen de tutela administrativa previsto expresamente en el TRRL, en su redacción originaria, y mantenido por la ley de Racionalización, puesto que una vez aprobado el expediente de ejercicio en régimen de monopolio de la actividad, dicho expediente se debe elevar completo al órgano competente en la Comunidad Autónoma, atribuyéndose igualmente de forma expresa y sin entrar en las disquisiciones que nos corresponderían sobre la vulneración o no de la potestad de la autoorganización autonómica, la competencia para aprobar sobre dicho asunto al Consejo de Gobierno en un plazo de 3 meses.

En ese aspecto la determinación a un órgano de la Comunidad autónoma ,u otro, por una norma de carácter estatal , no básico(recuérdese en ese sentido expresamente la STC 385/1993) no puede considerarse vinculante para la comunidad autónoma correspondiente, pudiendo esta cambiar sin problema el órgano que decidirá sobre el ejercicio de la actividad reservada , tal y como se desprende de la doctrina sobre organización establecida por el máximo interprete de la Constitución, en la STC 50/1999, sobre el título II de la LRJAPC. Así por ejemplo la LAULA ${ }^{72}$ andaluza suprimió el acuerdo del Consejo de gobierno.

Por tanto, en materia del ejercicio monopolístico de las actividades económicas, no se establece una reglamentación o regulación de carácter básico estatal que afecta al procedimiento y al órgano competente para su autorización, encontrándose por tanto, los informes y plazos obligatorios de cumplimiento de dicha determinación, quedando en manos de la Comunidad Autónoma la ejecución de dicha legislación, puesto que la decisión del Consejo de Gobierno se centrará en el ámbito lógicamente autonómico.

Cabe aquí plantearse, el contenido de dicha aprobación o no, si tiene una naturaleza reglada, esto es si se ha cumplido el contenido establecido por la ley en cuanto a tramitación del expediente, y es una de las actividades reservadas en virtud del artículo 86.2 LRBRL, a la entidad local, si puede o no el órgano autonómico apartarse de la propuesta municipal, en el supuesto que fuera propuesta, o de la decisión, si entendemos que es una decisión sometida a tutela o control sobre los aspectos de legalidad.

En nuestra opinión, optando claramente por la interpretación Constitucional sistemática del principio de autonomía local, nos encontraremos con una decisión autonómica, que podrá o no ser objetada por el órgano autonómico, pero tan solo basándose en cuestiones de legalidad, y no en ningún caso por cuestiones de oportunidad, puesto que la reserva ya ha sido establecida por ley, con competencia básica estatal, y el procedimiento es reglado,

71 Ramón Martín Mateo, “Especial referencia a la prestación bajo fórmulas societarias”, Revista de Estudios de la Administración Local y Autonómica, N²55-256, 1992, págs. 457-480.

72 Al respecto de dicha ley vid. Encarnación Montoya Martin, “Algunas notas sobre la Ley de autonomía local de Andalucía: los servicios públicos y la iniciativa económica local”, Cuadernos de derecho local, n² 24 págs. 144 y ss. 
siendo la verificación de la Comunidad Autónoma una tutela administrativa de control de mera legalidad, y no de oportunidad, puesto que nos encontraríamos sino ante una restauración de los controles establecidos antes de la Sentencia del Tribunal Constitucional 4/1981, que recuérdense han sido considerados como contrarios a la Autonomía Local.

De esta, y otras cuestiones de la LRSAL se deduce una cierta desconfianza hacia los municipios y prevalencia de las Comunidades Autónomas como en toda la ley, lo encontramos en el último párrafo de este nuevo artículo 97.2, TRRL(aunque provenga de la redacción originaria del TRRL), puesto que el plazo que se tarde en el supuesto que fuera necesario, para emitir el informe, o bien del Consejo de Estado, que se supone que son para las ciudades autónomas de Ceuta y Melilla, o bien de los Consejos Consultivos de las correspondientes Comunidades Autónomas, no computa a los efectos del plazo de 3 meses, debiéndose por tanto acudir a los plazos previstos para la emisión de dichos dictámenes, en las diferentes leyes reguladoras de los Consejos Consultivos, o en la ley orgánica 3/1980 reguladora del Consejo de Estado.

Así en concreto, en Andalucía se reservan a favor de los municipios, los servicios públicos básicos, que se recogen en los artículos 92.2 del estatuto de autonomía.

En ese sentido debemos de plantearnos esos servicios en relación con los previstos con la legislación básica de régimen local, que en opinión de Rivero Ysern73, no tienen coincidencia exacta.

\section{VII.3 Procedimiento para el ejercicio de la actividad económica bajo las reglas de la competencia}

Así debemos destacar, que para el ejercicio del ámbito de la entidad económica debe de tramitarse necesariamente un expediente, principal diferenciación entre una actividad privada y pública, en su origen, en tanto en cuanto, el carácter de vinculación al interés general que tiene cualquier administración, por determinación del artículo 103 de la Constitución, exige que el ejercicio de la actividad económica no redunde en el capricho o voluntad de un directivo por muy legítimamente democrático que sea, sino que además concurra un interés general en sentido estricto que se acredita mediante el correspondiente expediente, así ese expediente, es el que la reforma local se modifica introduciendo la vinculación lógicamente a la estabilidad presupuestaria, con el informe de la Intervención, y la acreditación concreta de qué asesoramientos ha recibido, quiénes han sido, cómo se ha tramitado, adicionando además el informe del órgano competente en defensa de la competencia.

Lógicamente después de la sentencia del Tribunal Constitucional al respecto ${ }^{74}$, será un órgano autonómico con las correspondientes consecuencias que de ello se pueda arrojar, que aunque contravengan el espíritu de la ley de unidad de mercado, se entiende a la luz de la indicada jurisprudencia del Constitucional y de la realidad de que la mayoría de las iniciativas económica de las AAPP locales tienen un evidente carácter infrautonómico.

Partiendo de dicha determinación lógicamente e independientemente de la mezcla entre actividades económicas, e inicios de servicios, que tantos problemas ha dado, pero que ha sido refrendada por el Tribunal Supremo en su sentencia de 1 de febrero de 2002(ARZ 1590) siempre que se realicen en régimen de empresa mercantil, por lo tanto, no cualquier actividad o servicio, sino aquellos que lógicamente se opten en la forma gestora por la prestación en régimen de sociedad mercantil.

Ahora bien, es el momento la forma gestora en la tramitación del expediente de inicio de la actividad, o esta elección en base a la potestad de autoorganización del artículo 30 del reglamento de servicios pueda optarse posiblemente.

Entendemos que no, puesto que, una u otra forma gestora tiene unas implicaciones que pueden tener no solo consecuencias jurídicas, sino determinaciones económicas, al respecto y máxime cuando nos encontramos ante actividades económicas que pudieran ser considerados de mercado y no de administración, en los términos de la SEC 95, y la SEC 2010.

Puesto que como indica la referida del Tribunal Supremo, caso "Iniciatives", la atención sustancialmente del carácter excepcional que supone la creación por la entidad local de una empresa sujeta al derecho mercantil, con la consiguiente sustracción de los principios del derecho público, cualquiera que sea la significación de las actividades de interés público a que se dedique su actividad.

73 Jose Luis Rivero Ysern, op. cit., “Manual de derecho local”, pág. 493.

74 A raíz de la Sentencia del Tribunal Constitucional 208/1999, de 11 de noviembre, se aprobó la Ley 1/2002, de 21 de febrero, de Coordinación de las Competencias del Estado y de las Comunidades Autónomas en materia de Defensa de la Competencia, con el objetivo de fijar el marco para el desarrollo de las competencias ejecutivas del Estado y de las Comunidades Autónomas previstas en la Ley 16/1989, de 17 de julio, hoy referida a la Ley 15/2007, de 3 de julio, previéndose, además, en la propia Ley 1/2002 la creación de órganos de defensa de la competencia en las Comunidades Autónomas que dispongan de competencias en esta materia., sobre este tema Jose Carlos Laguna de Paz “La defensa de la competencia”, como atribución de las comunidades autónomas”, Revista jurídica de Castilla y León, n²1, mayo 2010. 


\section{CONCLUSIONES}

A la vista de la nueva redacción de los arts. 86, 85 y 25 LRBRL y 97 TRRL debemos concluir la existencia de una modulación por vía de legislación básica estatal de la capacidad de iniciativa económica de las corporaciones locales, supeditando ${ }^{75}$ su absoluta potestad de autoorganización recogida en los arts. 30 del RSCL y $4^{\circ}$ de la LRBRL a la verificación, mediante expediente tramitado al efecto, que el ejercicio de la actividad no menoscabe el principio de estabilidad presupuestaria ${ }^{76}$.

Por otro lado se mantiene la tradicional distinción en la LRBRL de los dos incisos del art 128.2 CE sobre el ejercicio, o capacidad de ejercicio de la iniciativa económica de forma empresarial sometido a las reglas del mercado y la competencia y el ejercicio de actividades económicas en régimen monopolístico por habilitación legal.

En otro aspecto debemos destacar con Del Guayo ${ }^{77}$, en el sentido del mantenimiento de la distinción entre ejercicio de actividad económica de carácter empresarial general y ejercicio de actividad económica reservada, aunque sorprende que el mismo artículo 86, no ha supuesto una variación sustancial, si no que la LRSAL, viene a concretar que debe entenderse por oportunidad y conveniencia para el establecimiento de actividades económicas, no pudiéndose desligar esas circunstancias de oportunidad y conveniencia en las leyes económicas, esto es, a las circunstancias del momento.

En cuanto al procedimiento, debemos destacar que el expediente acreditativo que ha de tramitarse debe justificar la conveniencia y oportunidad de la medida, y ésta ha de justificarse en relación con la prestación por parte de la entidad de los servicios mínimos, con arreglo al coste de los servicios, tal y como se decía, no con arreglo al coste "estándar" de los servicios, como se decía en el texto del anteproyecto, si no, tener un análisis del mercado relativo a la oferta y a la demanda existente, a la rentabilidad y a los posibles efectos de la actividad local sobre la concurrencia empresarial ,no limitando por tanto, en contra de la Constitución, como se podía haber predicado por algún sector, la libertad de la entidades locales para llevar a cabo nuevas iniciativas económicas.

Subsiste la capacidad de las entidades locales, si cumplen con las reglas del desarrollo del art 135 CE, de hacer de empresarios , ajustándose a la libre competencia o ejerciendo las tres grandes materias reservadas de aguas , residuos y transporte.

En cualquier caso se hecha en falta una más contemporánea regulación de los expedientes de “municipalización” diferenciando los de creación de entidades para la gestión de servicios públicos (en especial los obligatorios del art 26 LRBRL) de la capacidad constitucional de iniciativa económica pública y por tanto local.

75 Algún autor la ha denominado postergación y así vid.: “Alcance de la provincialización de servicios locales en la Ley 27/2013, de Racionalización y sostenibilidad Local”, Casimiro López García, El Consultor de los Ayuntamientos, №2, Sección Colaboraciones, Quincena del 30 Ene. al 14 Feb. 2015, Ref. 167/2015, pág. 167, tomo 1, Editorial LA LEY.

76 Un análisis del concepto y evolución de la idea de la estabilidad presupuestaria lo tenemos en Fabio Pascua Mateo, “Las nuevas leyes de estabilidad presupuestaria: Aspectos formales y materiales”, Revista de Administración Pública, n¹58, mayo/agosto de 2002, págs. 119 y ss.

77 Iñigo Del Guayo Castiella, op. cit., “Nuevo régimen jurídico de los servicios públicos locales, tras la reforma de la ley $27 / 2013$, de 27 de diciembre, de Racionalización y Sostenibilidad de la Administración Local”, págs. 490 a 499 de El Consultor de los Juzgados y los Ayuntamientos, $\mathrm{n}^{\circ}$ 5, 2014, 15 de marzo, y en concreto pág. 493. 
